\title{
Proyectos fallidos de desarrollo rural en Andalucía
}

Failed projects and land development in Andalusia

\author{
José Antonio Cañete Pérez
}

joseaca@ugr.es

\section{Eugenio Cejudo García}

joseaca@ugr.es

\author{
Francisco Antonio Navarro Valverde \\ favalver@ugr.es \\ Departamento de Geografía Humana \\ Universidad de Granada (España)
}

\section{Resumen}

Tradicionalmente las investigaciones sobre los Programas de Desarrollo Rural han abordado su efectividad y sus repercusiones sociales y territoriales centradas en los proyectos ejecutados, sin abordar el estudio de aquellos que no lo fueron - denominados por nosotros como fallidos- $y$, por tanto, sin analizar sus causas, tipologías, promotores o distribución territorial, perdiéndose así una excelente oportunidad de aprender de los motivos por lo que no se ejecutaron con su subvención. El presente trabajo realiza un análisis de los proyectos del periodo 2002-2008 en Andalucía que, habiendo sido aprobados y en los que se ha firmado el correspondiente convenio de ejecución, no se llegaron a realizar a su amparo. La investigación realizada constituye un acercamiento a estos Programas desde una óptica diferente y novedosa, en la que se aborda su distribución espacial, el tipo de promotor, su tipología, los niveles de inversión frustrados y las causas que motivaron su abandono. Para ello, se ha trabajado a dos escalas diferentes, la municipal y la de cada uno de los territorios de los Grupos de Acción Local para toda Andalucía en base a los datos por expedientes aportados por la Junta de Andalucía. 
Palabras clave: leader; desarrollo rural; desequilibrio territorial; emprendedores rurales.

\begin{abstract}
Traditionally, research on Rural Development Programmers (RDPs) has addressed their effectiveness and their social and territorial repercussions focused on projects implemented, without considering the study of those who were not - called by us as failed - and, therefore, without analyzing their causes, typologies, promoters or their territorial distribution; and so, the study of these ones is an excellent opportunity to learn the reasons why they were not executed with a grant. The present work analyzes the failed projects of the period 2002-2008 in Andalusia that, having been approved and in which with the corresponding agreement of execution signed, did not execute under the cover of RDPs. The research carried out is an approach to these programmers from a different and new approach, which studies their spatial distribution, the type of promoters, their typologies, the levels of investment frustrated and the causes that motivated their retirement. For this, the study has been focused on two different scales, municipal level and Local Action Group level, for all Andalusia region, and according to the data given by the Andalusian Government.
\end{abstract}

Key words: leader; developing rural; territorial imbalance; rural enterprising.

\title{
1 Introducción
}

El análisis de los Programas de Desarrollo Rural (PDR), centrados en LEADER o PRODER, ha constituido una línea de investigación muy frecuente en los trabajos relacionados con el mundo rural ya sea utilizando datos globales a nivel autonómico, ya centrados en el estudio de diferentes Grupos de Acción Local (GAL) o, más raramente, con datos municipales de toda una comunidad autónoma.

Las temáticas y los enfoques abordados, igualmente, han sido muy variados, incidiendo, entre otros, en el reparto territorial de las inversiones (Cejudo \& Navarro, 2003, 2009), en la tipología de sus beneficiarios (Plaza, 2005; Böcher, 2008; Dargan \& Shucksmith, 2008; Buciega, 2012; Bosworth et al., 2015), en sus efectos sobre el empleo, en su aportación a la diversificación económica de las zonas rurales, en la mejora de la calidad de vida de sus habitantes (Nieto \& Gurría, 2005; Márquez et al., 2006; Esparcia \& Escribano, 2012; Martínez et al., 2015). Las referencias bibliográficas que se pueden encontrar al respecto son numerosas tanto a nivel andaluz, como de las demás comunidades autónomas españolas o de los países europeos (Osti, 2000; Shortall, 2008; Nardone et al., 2010; Gardner, 2011. Es poco discutible que durante los últimos 25 años la iniciativa LEADER ha contribuido a incorporar nuevos principios a las recientes teorías del desarrollo neo-endógeno, combinando y complementando los enfoques ascendente y descendente, las fuerzas endógenas y exógenas, la participación y las relaciones internas y 
externas, y los instrumentos de gobernanza y de gobierno. Todo ello en un contexto teórico marcado tanto por las múltiples variaciones terminológicas usadas como por la desconexión existente entre los diferentes cuerpos teóricos que se abordan este nuevo enfoque. En la actualidad, la mayoría de la literatura europea ya habla simplemente de desarrollo rural en el que lo relevante que se defiende por los diversos autores es su carácter endógeno, local e integrado (Guinjoan et al., 2016). Este nuevo enfoque ha sido catalogado como un nuevo paradigma en el que sustentar la implementación de las políticas de desarrollo rural, en nuestro caso europeas (Kitchen \& Marsden, 2009; Woods, 2011).

Las visiones críticas de los Programas de Desarrollo Rural han sido también un punto común en la mayor parte de estas investigaciones. Los efectos de estas políticas en el marco europeo ofrecen resultados muy dispares según países y regiones y ello ha sido puesto de manifiesto en investigaciones muy diversas (Gadner, 2011; Augustyn \& Nemes, 2014). Se resaltan, frecuentemente, aspectos como el progresivo abandono, por motivos diversos, de algunos de los principios básicos de la filosofía LEADER como su enfoque ascendente, bottom-up (Navarro, Woods \& Cejudo, 2016); los efectos perniciosos de estas políticas, que lejos de favorecer el reequilibrio territorial, han propiciado el agravamiento de los desequilibrios existentes en algunos territorios, acentuando las desigualdades que pretendían subsanar o, al menos, corregir (Cejudo \& Navarro, 2012; Casellas et al., 2013), por citar sólo dos aspectos que entroncan de forma clara con el trabajo que se presenta.

Sin embargo un rasgo común a todas ellas es que se basan en el análisis de los proyectos, lógicamente, ejecutados, analizando las diversas repercusiones en sus respectivos ámbitos de referencia. Los proyectos aprobados pero no ejecutados, que de forma sintética llamamos "fallidos", son excluidos de este análisis al no llevarse a cabo. Además, las grandes cifras, los valores medios de cualquier variable, en ámbitos extensos tienden a difuminar realidades complejas que pueden esconder la efectividad real de cualquier política de desarrollo y que sólo es visible si se desciende al nivel de información primaria como es trabajar con cada uno de los expedientes presentados en los diferentes $G A L$, en nuestro caso de Andalucía. Si en un municipio cualquiera en el marco de un Programa de Desarrollo Rural como el LEADER se aprueba un determinado número de proyectos, en los que se aceptan las inversiones previstas, se conceden las subvenciones pero sin embargo no se ejecuta ninguno de ellos, tal y como hemos podido comprobar, resulta evidente que algo está fallando. Se dejan fuera, reclama Rodríguez et al., demasiadas realidades y situaciones que no encajan en el modelo sobre qué está ocurriendo y cómo corregir las situaciones negativas que se aprecian en el análisis del presente. Tanto en un ámbito como en otro, es importante caer en la cuenta de la presencia del fracaso, de la ineficiencia, de la novedad sorpresiva, para evitar explicaciones sesgadas que dejen de antemano al margen a quienes no 
encajan en el engranaje de esos modelos que tratan de explicar la acción social (Rodríguez, Tejero \& Sánchez, 2014, 103-4).

Este tipo de análisis, de los proyectos fallidos a nivel de municipio para unidades territoriales amplias como es una Comunidad Autónoma, no tiene precedentes en la bibliografía que analiza los Programas de Desarrollo Rural, o al menos no los hemos encontrado. Las referencias más próximas al tipo de análisis que se pretende realizar, pero referidas a proyectos concretos y no con la amplitud territorial que aquí se propone, las encontramos en los trabajos de Alonso y Macías (2014) o de Arcilla y López (2015), sin que se planteen con el carácter global y territorial que fundamenta la investigación por nosotros realizada. Desde otra perspectiva, el término "fallido" ha estado presente en aportaciones críticas sobre programas e iniciativas como LEADER o PRODER, incidiendo en la contradicción entre sus objetivos iniciales y las realidades territoriales de los espacios en los que se ha invertido aunque éstas no han dejado de ser valoraciones globales sobre la eficacia de estos programas, sustentadas en los efectos de la inversión realizada. Desde esta perspectiva, son numerosos los trabajos que, de una forma u otra, cuestionan la efectividad de este tipo de inversiones lo que hace que se puedan catalogar como "iniciativas fallidas" en nuestra terminología (Márquez et al., 2006; Gordo, 2011; Cejudo \& Navarro, 2012; Navarro, Cejudo \& Maroto, 2014; Martínez et al., 2015). Sin embargo, en ningún caso han abordado lo "aprobado y no ejecutado" que es lo que aquí nos ocupa. Es, por tanto, un acercamiento novedoso, que puede, además de aportar una visión inexplorada desde el punto de vista científico a este tipo de estudios, ofrecer enseñanzas interesantes en la gestión de los mismos.

\section{Metodología y ámbito de análisis}

El objetivo de nuestro trabajo es el análisis de los proyectos fallidos en toda Andalucía durante el periodo de ejecución 2002-2008 a distintas escalas (Comunidad Autónoma, GAL y municipios). Para ello, nos centraremos, por un lado, en la tipología de los proyectos, de emprendedores afectados y de las casusas últimas de estos abandonos; por otro, estudiaremos la incidencia territorial a nivel local de dichos proyectos fallidos en comparación con los aprobados para todos los municipios andaluces.

La comunidad autónoma de Andalucía con más de 770 municipios (el 9,48 \% del total nacional) y algo más del $17 \%$ de la superficie nacional $\left(87598 \mathrm{~km}^{2}\right.$ ) es la segunda más extensa del conjunto del estado español después de la de Castilla y León. Sin embargo, atendiendo a su población estamos ante la más poblada, pues sus 8400000 habitantes la convierten en la de mayor peso demográfico del conjunto nacional. Si se tienen en cuenta estas magnitudes en cuanto al tamaño del ámbito de estudio y la importancia territorial del mismo, se puede apreciar, en su justa medida, lo que significa que el estudio sobre los proyectos fallidos en Andalucía parta del nivel de desagregación máximo posible; esto es el expediente administrativo de cada uno de los proyectos 
aprobados. Por agrupación se obtienen los datos a nivel municipal, de GAL y de comunidad autónoma.

La información tiene su origen en la explotación de la base de datos a nivel de expediente de los programas LEADER y PRODER en Andalucía en el periodo 2002-2008 facilitada por la Dirección General de Desarrollo Sostenible de la Consejería de Agricultura, Pesca y Desarrollo Rural de la Junta de Andalucía. Esta secuencia temporal constituye un marco unitario en cuanto a Planes de Desarrollo Rural, objetivos de los mencionados planes, criterios y prioridades en las adjudicaciones, y como no, equipos (GAL) que han gestionado los fondos disponibles. A ello hay que añadir la unidad territorial, ya que en el periodo posterior 2007-13 se modificaron el número de Grupos y su composición. Otro de los aspectos esenciales para habernos centrado sólo en este periodo de programación es el de homogeneizar el contexto socioeconómico en el que se produjeron estos fracasos de los que tenemos todos los datos. El periodo de programación siguiente viene marcado por la crisis económica y financiera -frente al de bonanza analizado-, lo que distorsionaría el análisis hasta no poder disponer de datos globalmente comparables con el periodo anterior. El análisis por periodos de programación es, por tanto, necesario y ofrece coherencia a los resultados obtenidos, no siendo conveniente su mezcla.

El estudio se ha centrado en las actuaciones aprobadas pero no ejecutadas dentro de la Iniciativa LEADER+ y PRODER-Andalucía (Eje 7, medidas 7.55 sobre diversificación agraria y 7.59 sobre desarrollo endógeno de zonas rurales no ligadas a actividades agrarias). En relación con LEADER+ se han estudiado, por un lado, el Eje 1 relativo a la Estrategia de desarrollo rural puesta en marcha por cada GAL y, por otro, el Eje 2.1 relativo a la Cooperación interterritorial. Dicha estrategia, según las indicaciones de la Comisión, se debe desarrollar de forma integrada, inscribirse en las políticas comunitarias, nacionales y regionales, realizarse prestando especial atención a la valorización de los recursos específicos de cada territorio, ejecutarse bajo un prisma de defensa e impulso de la calidad y caracterizarse por un carácter notablemente experimental, innovador y piloto. Además, debe estar fundamentada en otras dos cuestiones de especial trascendencia. La cooperación y la transferencia metodológica, de forma que las mejoras, los avances, las realizaciones que se alcancen en unos territorios sean intercambiadas y transferidas con los demás, y que las acciones de realicen en un entorno de cooperación integrada.

La unificación de los datos de LEADER y PRODER se ha podido realizar con pequeñísimos ajustes ya que comparten la mayoría de los campos. Sólo en el caso de la "medida" en la que se inserta el proyecto se producían problemas que se han solventado a través del uso de un campo común: "ámbito", cuya codificación permite unificar las mismas líneas de intervención en uno y otro Programa aunque la estructura y denominación de algunos campos fuera diferente. 
Se trata de proyectos que habían presentado la solicitud de subvención, momento en el cual también presentaron la memoria descriptiva del proyecto, las facturas pro-forma, el proyecto de obra en su caso, la documentación relativa a la identidad de la persona solicitante, declaraciones responsables varias, el certificado de la entidad bancaria donde se realizaría la transferencia y la acreditación encontrarse al corriente de sus obligaciones fiscales. Tras ello, se realiza un análisis inicial de la solicitud en un plazo de un mes para estimar si se adecúa o no a las actuaciones subvencionables y, en su caso, se procede al levantamiento del acta de no inicio de la inversión. Posteriormente, se informa a la Delegación Provincial de Agricultura y Pesca, en nuestro caso, de la Junta de Andalucía, para que en un plazo de un mes comunique al GAL si la intervención cumple con las condiciones de legalidad. En el siguiente paso, el equipo técnico del GAL elabora un informe técnico-económico de la solicitud a través del cual se determina la subvención final que puede alcanzar la inversión. El Responsable Administrativo Financiero (RAF) del GAL realiza una reserva presupuestaria a favor del solicitante, siendo el Consejo Territorial del GAL el que acuerda la concesión de la subvención en base al Informe Técnico-Económico y el Informe del RAF e informa al solicitante de la aprobación de la subvención concedida. Por último, se alcanza la fase de formalización del contrato de ayuda y, por tanto, de su ejecución, momento en el que se quedaron los proyectos estudiados a los que hemos denominado fallidos. Es decir, estos expedientes no llegaron a alcanzar el resto de fases: solicitud de pago de la subvención, el acta de finalización de la inversión, y por último, la certificación de gastos.

Hemos de aclarar que son proyectos que han podido finalizarse aunque, en ningún, caso al amparo de las subvenciones y bajo la protección de LEADER O PRODER. Fallido, por tanto, no implica, necesariamente, la no realización del proyecto. Hay casos en los que éstos si han visto la luz. Hecho éste que cuestiona alguno/s de los procesos, tiempos, nivel de asesoramiento, trabas administrativas, cuantía de la ayuda, etc., que pueden hacer que iniciativas viables, tal y como lo demuestra su realización, se vean excluidas de estos Programas. Ponemos el acento, alejándonos de una perspectiva institucional/formal y meramente cuantitativista, en los colectivos y territorios menos favorecidos de estos programas, que suelen coincidir con las mujeres y los jóvenes así como territorios montanos y del rural profundo, que merecen una atención especial por su situación objetivamente desventajosa y, a pesar de ello, por su potencial rol dinamizador de la sociedad rural como posible freno del éxodo rural o de la erradicación planteamientos excluyentes y patriarcalistas que aún persisten, especialmente en los territorios y colectivos reseñados (Cruces \& Palenzuela 2006; Palenzuela \& Cruces, 2011). Hemos optado, por tanto, por una metodología que pone en relación datos cuantitativos estadísticos con otros cualitativos que parten del propio discurso de los informantes. Se han tenido, también a su vez, una serie de entrevistas en profundidad, (no estructuradas), con el personal técnico y gerentes de los GAL, con el objeto de conocer las causas últimos de estos expedientes fallidos, y en su caso la posible ejecución por otros medio de 
financiación. Estas entrevistas se han llevado a cabo con los Grupos de Acción Local de la provincia de Granada, que pueden servir de muestra del conjunto de Andalucía.

Para contrastar la importancia de los fallidos, las referencias a los proyectos realmente ejecutados se hacen inevitables ya que no sólo comparten la misma fuente de información sino que son el contrapunto que permite valorar su incidencia territorial.

Esta información específica se ha complementado con otra de carácter estadístico que ha permitido la elaboración de indicadores básicos y correlaciones estadísticas. Esta información ha sido obtenida de la aplicación web del Sistema de Información Multiterritorial de Andalucía (SIMA) del Instituto de Estadística y Cartografía de la Junta de Andalucía. De este mismo organismo son los ámbitos administrativos municipales que dan soporte a la cartografía, y por agregación de estos a los ámbitos de los GAL.

El análisis territorial, dada la amplitud de la comunidad autónoma de Andalucía, se ha planteado a tres escalas: datos globales de la comunidad autónoma, a escala GAL y de municipio. Considerándose que es el análisis GAL el más adecuado para los objetivos de esta investigación.

De igual modo, debe señalarse que se ha primado la visualidad de los resultados, ya que es a través de la cartografía elaborada como mejor se aprecian las variaciones territoriales. Es por ello que hemos reducido, en la medida de lo posible, las tablas estadísticas, fundamentalmente, al conjunto de Andalucía.

La hipótesis de partida de la investigación realizada es que la distribución territorial de los proyectos fallidos de las Iniciativas LEADER y PRODER en Andalucía en el periodo 2002-2008 responde a la misma lógica espacial de los proyectos ejecutados, concentrándose en las zonas más dinámicas donde los proyectos de iniciativa privada son mayoritarios, frente a aquellas zonas en donde la administración pública es la única inversora y en consecuencia con un porcentaje menor de fallidos. Reforzándose así los aspectos negativos asociados a LEADER.

\section{Resultados}

\subsection{La incidencia de los proyectos fallidos en el conjunto de Andalucía}

En lo que concierne a la comunidad autónoma de Andalucía y al periodo 2002-2008, estos proyectos fallidos suponen el 13,4\% del total (Tabla 1), mayoritariamente de ámbito municipal, ya que los no municipalizados ${ }^{1}$ representan una pequeña parte de esta cifra.

1 Se entiende por proyectos no municipalizados aquellos en los que la inversión se aplica a más de un municipio. 
Tabla 1. Proyectos Fallidos y Aprobados en los PDR Andalucía (2002-2008)

\begin{tabular}{|c|c|c|c|c|c|c|c|c|c|c|c|c|}
\hline \multirow{2}{*}{$\begin{array}{l}\text { Tipo de } \\
\text { Proyecto }\end{array}$} & \multicolumn{3}{|c|}{ LEADER 1} & \multicolumn{3}{|c|}{ LEADER 2.1} & \multicolumn{3}{|c|}{ PRODER } & \multicolumn{3}{|c|}{ TOTAL } \\
\hline & Fallido & Ejecutado & Total & Fallido & Ejecutados & Total & Fallido & Ejecutado & Total & Fallido & Ejecutado & Total \\
\hline \multicolumn{13}{|c|}{ VALORES ABSOLUTOS } \\
\hline $\mathrm{N}^{\circ}$ proyectos & 263 & 2143 & 2406 & 48 & 229 & 277 & 970 & 5849 & 6819 & 1281 & 8221 & 9502 \\
\hline Municipalizados & 240 & 1663 & 1903 & 42 & 163 & 205 & 924 & 4924 & 5848 & 1206 & 6786 & 7982 \\
\hline Sin municipalizar & 23 & 480 & 503 & 6 & 66 & 72 & 46 & 925 & 971 & 75 & 1.435 & 1510 \\
\hline \multicolumn{13}{|c|}{ VALORES RELATIVOS } \\
\hline $\mathrm{N}^{\circ}$ proyectos & 10,93 & 89,07 & 100,00 & 17,33 & 82,67 & 100,00 & 14,22 & 85,78 & 100,00 & 13,48 & 86,52 & 100,00 \\
\hline Municipalizados & 12,61 & 87,39 & 100,00 & 20,49 & 79,51 & 100,00 & 15,80 & 84,20 & 100,00 & 15,16 & 84,84 & 100,00 \\
\hline Sin municipalizar & 4,57 & 95,43 & 100,00 & 8,33 & 91,67 & 100,00 & 4,74 & 95,26 & 100,00 & 4,85 & 95,15 & 100,00 \\
\hline
\end{tabular}

Fuente: elaboración propia a partir de la

Dirección General de Desarrollo Sostenible (2000-2008)

En cifras absolutas los proyectos fallidos han sido 1281 de un total de 9502 proyectos aprobados. Correspondiendo 75 a aquéllos que se desarrollaron en más de un municipio y el resto a los que lo hacían en uno sólo. Atendiendo a la diferente procedencia de los fondos estas cifras constatan otro hecho importante, y es que en su mayor parte los proyectos aprobados pero no ejecutados correspondían a PRODER (el 75,72\%). Información que se encuentra más detallada en la Tabla 2.

Tabla 2. Proyectos Fallidos en los PDR según Programa y causa. Andalucía (2002-2008)

\begin{tabular}{|l|r|r|r|r|r|r|r|r|}
\hline Tipo de Proyecto & \multicolumn{2}{|c|}{ LEADER 1 } & \multicolumn{2}{l|}{ LEADER 2.1 } & \multicolumn{2}{c|}{ PRODER } & \multicolumn{2}{|c|}{ TOTAL } \\
\hline Finalizado & 0 & 0,00 & 0 & 0,00 & 8 & 0,82 & 8 & 0,62 \\
\hline Renuncia & 256 & 97,34 & 47 & 97,92 & 858 & 88,45 & 1.161 & 90,63 \\
\hline Desestimado & 3 & 1,14 & 0 & 0,00 & 15 & 1,55 & 18 & 1,41 \\
\hline Sin finalizar & 4 & 1,52 & 1 & 2,08 & 89 & 9,18 & 94 & 7,34 \\
\hline Total Fallidos & 263 & 100,00 & 48 & 100,00 & 970 & 100,00 & 1.281 & 100,00 \\
\hline
\end{tabular}

Fuente: elaboración propia a partir de la

Dirección General de Desarrollo Sostenible (2000-2008)

De las cuatro categorías establecidas por la administración andaluza como causas por las que dichos proyectos no se llegaron a ejecutar, la más frecuente en todos los Programas ha sido "la renuncia", ya que como tal se considera en el 90,63\% de los casos. Sin embargo la realidad es más compleja, ya que bajo este término se engloban situaciones muy diferentes que van desde la renuncia en sentido estricto hasta la rescisión del contrato, y por tanto la denuncia del mismo por parte de la administración, frecuentemente por el incumplimiento de los plazos para llevar a cabo la ejecución del proyecto. Las causas de este incumplimiento fueron, a su vez, variadas:

- en muchos casos lo que ponen de manifiesto es la falta de madurez de dichos proyectos al no sopesar suficientemente los solicitantes los requerimientos de los mismos, tales como la necesidad de redactar proyectos previos (de construcción, de urbanización, etc.) o de obtener autorizaciones o permisos administrativos; 
- no disponer de la financiación privada (aunque en este periodo el acceso al préstamo bancario no suele ser la causa principal de la renuncia);

- no poseer las autorizaciones pertinentes en el momento de finalización del proyecto (en cuyo caso debiera revisarse como se ha realizado la gestión y seguimiento del proyecto por parte del $\mathrm{GAL})$;

- sin olvidar, además y tal y como se indicó en el apartado anterior, el largo y complejo proceso administrativo al que deben hacer frente los solicitantes de estas ayudas.

Según informaciones manifestadas por los técnicos y gerentes responsables de gestionar estos proyectos en los GAL de la provincia de Granada, bajo este epígrafe de renuncia solían encuadrarse situaciones que podríamos denominar de "renuncia forzosa". Aunque minoritarias las otras modalidades como son "finalizado", "desestimado" o "sin finalizar" recogen situaciones administrativas diversas: unas veces para proceder a tramitar el reintegro de las subvenciones concedidas por no justificar adecuadamente los pagos a sus proveedores, otras por la carencia de documentación que certifique plenamente las partidas ejecutadas.

Tabla 3. Proyectos Fallidos según destinatario en los PDR de Andalucía (2002-2008)

\begin{tabular}{|l|r|r|r|r|r|r|}
\hline \multicolumn{1}{|c|}{ Tipo de Destinatario } & Fallido & Ejecutado & Aprobado & Fall/Ejec & Fall/Apro & \%_Fall \\
\hline Autónomo mujer & 129 & 471 & 600 & 27,39 & 21,50 & 10,07 \\
\hline Autónomo hombre & 192 & 701 & 893 & 27,39 & 21,50 & 14,99 \\
\hline Corporación local & 188 & 2066 & 2254 & 9,10 & 8,34 & 14,68 \\
\hline Cooperativa o SAT y Soc. Resp. Limitada & 26 & 211 & 237 & 12,32 & 10,97 & 2,03 \\
\hline Sociedad Mercantil & 223 & 1107 & 1330 & 20,14 & 16,77 & 17,41 \\
\hline Sociedad laboral & 37 & 176 & 213 & 21,02 & 17,37 & 2,89 \\
\hline GAL o asociaciones & 126 & 2030 & 2156 & 6,21 & 5,84 & 9,84 \\
\hline Otras entidades & 54 & 359 & 413 & 15,04 & 13,08 & 4,22 \\
\hline Autónomo mujer joven & 52 & 136 & 188 & 38,24 & 27,66 & 4,06 \\
\hline Autónomo hombre joven & 80 & 223 & 303 & 35,87 & 26,40 & 6,25 \\
\hline Cooperativa o SAT (+25\% son jóvenes). & 5 & 23 & 28 & 21,74 & 17,86 & 0,39 \\
\hline Cooperativa o SAT (+25\% son mujeres) & 7 & 31 & 38 & 22,58 & 18,42 & 0,55 \\
\hline Entidad de economía social & 2 & 15 & 17 & 13,33 & 11,76 & 0,16 \\
\hline Sociedad Limitada & 20 & 99 & 119 & 20,20 & 16,81 & 1,56 \\
\hline Sociedad mercantil +25\% son jóvenes) & 57 & 267 & 324 & 21,35 & 17,59 & 4,45 \\
\hline Sociedad mercantil (+25\% mujeres jóvenes) & 19 & 49 & 68 & 38,78 & 27,94 & 1,48 \\
\hline Otras Sociedades mercantiles & 10 & 40 & 50 & 25,00 & 20,00 & 0,78 \\
\hline Sociedad laboral limitada & 23 & 60 & 83 & 38,33 & 27,71 & 1,80 \\
\hline Comunidad de Bienes & 9 & 14 & 23 & 64,29 & 39,13 & 0,70 \\
\hline Asociación o fundación (+25\% son jóvenes) & 2 & 6 & 8 & 33,33 & 25,00 & 0,16 \\
\hline Asociación o fundación (+25\% son mujeres) & 6 & 63 & 69 & 9,52 & 8,70 & 0,47 \\
\hline Otras Asociaciones & 0 & 4 & 4 & 0,00 & 0,00 & 0,00 \\
\hline Otras entidades (+25\% son jóvenes) & 5 & 16 & 21 & 31,25 & 23,81 & 0,39 \\
\hline Otras entidades (+25\% son mujeres) & 5 & 39 & 44 & 12,82 & 11,36 & 0,39 \\
\hline Otras & 4 & 15 & 19 & 26,67 & 21,05 & 0,31 \\
\hline TOTAL & 1281 & 8221 & 9502 & 15,58 & 13,48 & 100,00 \\
\hline
\end{tabular}

Fuente: elaboración propia a partir de la

Dirección General de Desarrollo Sostenible (2000-2008) 
Una vez evaluada para el conjunto de Andalucía la importancia de estos proyectos fallidos, y sobre los que se realiza posteriormente un análisis territorial a nivel de GAL y de municipio, interesa conocer, por un lado, cuáles son los destinatarios más afectados, y por tanto con mayor número de proyectos fracasados, y, por otro, qué tipología de proyectos son los que se encuentran mayoritariamente en esta situación.

Aunque en una primera visión ya se constata una cierta concentración de los proyectos fallidos en los grupos de autónomos, sociedades mercantiles y corporaciones locales (Tabla 3), tal y como permite comprobar la última de las columnas de la tabla, los datos de mayor interés, sin embargo, se obtienen de su comparación con los proyectos aprobados en los mismos grupos de destinatarios. Los resultados obtenidos no hacen más que corroborar las hipótesis manifestadas en otros trabajos sobre la incidencia de este tipo de programas de desarrollo rural que no consiguen propiciar suficientemente la participación de los grupos sociales más vulnerables, a la vez que más necesitados, como son el colectivo de la mujeres y los jóvenes (Navarro, Cejudo \& Maroto, 2014; Cejudo, Navarro \& Camacho, 2017).

\section{Tabla 4. Proyectos Aprobados y Fallidos según principales destinatarios en los PDR de Andalucía (2002-2008)}

\begin{tabular}{|c|c|c|c|c|c|c|c|c|c|}
\hline \multirow{2}{*}{ Tipo de destinatario } & \multicolumn{2}{|c|}{ Fallido } & \multicolumn{2}{|c|}{ Ejecutado } & \multicolumn{2}{|c|}{ Aprobado } & \multirow{2}{*}{ Fall/Ejec } & \multirow{2}{*}{ Fall/Apro } & \multirow{2}{*}{ \%Fall } \\
\hline & $\mathrm{N}^{\circ}$ & $\%$ & $\mathrm{~N}^{\circ}$ & $\%$ & $\mathrm{~N}^{\circ}$ & $\%$ & & & \\
\hline Autónomo mujer & 129 & 10,07 & 471 & 5,73 & 600 & 6,31 & 27,39 & 21,50 & 10,07 \\
\hline Autónomo hombre & 192 & 14,99 & 701 & 8,53 & 893 & 9,40 & 27,39 & 21,50 & 14,99 \\
\hline Autónomo mujer joven & 52 & 4,06 & 136 & 1,65 & 188 & 1,98 & 38,24 & 27,66 & 4,06 \\
\hline Autónomo hombre joven & 80 & 6,25 & 223 & 2,71 & 303 & 3,19 & 35,87 & 26,40 & 6,25 \\
\hline Total Autónomos & 453 & 35,36 & 1.531 & 18,62 & 1984 & 20,88 & 28,41 & 22,83 & 35,36 \\
\hline Sociedad Mercantil & 223 & 17,41 & 1.107 & 13,47 & 1330 & 14,00 & 20,14 & 16,77 & 17,41 \\
\hline Soc. Mercantil (+25\% jóvenes) & 57 & 4,45 & 267 & 3,25 & 324 & 3,41 & 21,35 & 17,59 & 4,45 \\
\hline Soc. Mercantil (+25\% mujeres jóvenes) & 19 & 1,48 & 49 & 0,60 & 68 & 0,72 & 38,78 & 27,94 & 1,48 \\
\hline Total Soc. Mercantiles & 299 & 23,34 & 1.423 & 17,31 & 1722 & 18,12 & 21,01 & 17,36 & 23,34 \\
\hline Corporación local & 188 & 14,68 & 2.066 & 25,13 & 2254 & 23,72 & 9,10 & 8,34 & 14,68 \\
\hline GAL o asociaciones & 126 & 9,84 & 2.030 & 24,69 & 2156 & 22,69 & 6,21 & 5,84 & 9,84 \\
\hline Entidades públicas & 314 & 24,51 & 4.096 & 49,82 & 4410 & 46,41 & 7,67 & 7,12 & 24,51 \\
\hline TOTAL & 1281 & 100,00 & 8221 & 100,00 & 9502 & 100,00 & 15,58 & 13,48 & 100,00 \\
\hline
\end{tabular}

Fuente: elaboración propia a partir de la

Dirección General de Desarrollo Sostenible (2000-2008)

En la Tabla 4 hemos reducido las tipologías existentes a tres grandes categorías representadas por los autónomos, las sociedades mercantiles y las entidades públicas, incluyendo como tal a los GAL, en la medida en que ellas concentran el 83,2\% de los proyectos fallidos totales (1066), porcentaje muy similar al de proyectos ejecutados, $85,8 \%$, y aprobados, 85,9\%.

Es evidente la relación existente entre los mayores destinatarios de los proyectos aprobados en este periodo y los proyectos fallidos por cada uno ellos. Los principales promotores por número de proyectos aprobados (que no por cuantía de la inversión) han sido las corporaciones locales 
seguidas de los propios GAL y otras Asociaciones que han concentrado el 23,72\% y 22,69\% de los proyectos tramitados en este periodo. A estos le siguen el conjunto de los autónomos con el $20,88 \%$ y con un $18,12 \%$ el conjunto de las sociedades mercantiles. Ahora bien, en los proyectos fallidos estas proporciones no se mantienen, al contrario se invierte de forma clara en la medida en que es el colectivo de los autónomos en su conjunto el que concentra el mayor porcentaje de proyectos fallidos con el 35,36\% del total, seguidos de las entidades públicas con un 24,51\% y las sociedades mercantiles con el 23,34\%. Antes de entrar en más detalles, es evidente que es el autónomo el que registra un nivel de fracaso mayor que las otras dos tipologías de emprendedores debido a cuestiones relacionadas con la solvencia económica, la capacidad de endeudamiento, el potencial humano y técnico del que disponen, el insuficiente asesoramiento por parte de los GAL, etc., frente al caso de las sociedades mercantiles o los promotores públicos. Además, en estos últimos, se une el hecho de apostar por proyectos de diversa índole y tipología -formativa, de difusión, promoción, etc. - que presentan unos altos niveles de subvención que pueden alcanzar el 100\% de la inversión prevista, nada que ver la situación del autónomo. Aspecto que resulta crucial en la medida en que el trabajo autónomo ha jugado un papel esencial en el mercado de trabajo de nuestro país (Guzmán, Cuevas \& Romero, 2005) que se acrecienta en nuestros días como fórmula para combatir el desempleo generado por la actual crisis económica (Riesco, 2016). Ello sin olvidar el constante incremento de la tasa de salarización de nuestro mercado de trabajo que se dispara de forma clara durante la bonanza económica del periodo 2000-2007 gracias a la incorporación masiva de la mujer al mercado de trabajo y la llegada de población inmigrante (Prieto \& Pérez de Guzmán, 2013; Cachón, 2009).

Pero, al menos, otras dos cuestiones son evidentes en esta Tabla 4. Si tomamos como referencia la ratio entre los fallidos y ejecutados se comprueba, de un lado, que tanto en el colectivo de autónomos como en el de las sociedades mercantiles los valores más altos los encontramos en el colectivo de los jóvenes con índices que superan la media de los autónomos en más de 7 puntos. De otro, que esta penalización que afecta al colectivo joven se incrementa y adquiere tintes muy preocupantes si de las mujeres hablamos ya que dentro del colectivo joven sus valores superan a los del varón en 2,5 puntos, si de autónomos hablamos, y en más de 17 en las sociedades mercantiles. Es más, en estas dos categorías los fallidos representan casi el $40 \%$ de los ejecutados. Por el contrario, las entidades públicas, corporaciones locales y GAL, presentan una ratio media de 7,67, siendo inferior a ella en los GAL y superior en los Ayuntamientos.

De esta forma el perfil del destinatario fallido se podría resumir en emprendedor joven, mayoritariamente mujer, que adopta formas societarias débiles tales como comunidades de bienes o autónomo, que no consiguen llevar a cabo los proyectos aun habiendo sido aprobados y teniendo subvenciones. Esta radiografía se agrava si se tiene en cuenta que para el conjunto de Andalucía el peso de este tipo de destinatarios es minoritario pues los autónomos jóvenes apenas 
representan el 5\% del total de los proyectos aprobados: 1,97\% para las mujeres y 3,18 \% para los hombres. Frente a ellos casi la mitad de los aprobados son liderados por las entidades públicas, lo que, más allá del debate sobre la participación de las corporaciones locales en este tipo de iniciativas, pone en evidencia la necesidad de incrementar el emprendimiento privado en este tipo de iniciativas.

Se puede afirmar con rotundidad que, en gran medida, gracias a los PDRs han aparecido emprendedoras en el medio rural, cosa que hace unas décadas era imposible pensar, especialmente, tras la denominada "huida ilustrada" (Camarero, 2009; Ministerio de Medio Ambiente y Medio Rural y Marino, 2011), y que con el pretexto de estas nuevas ayudas se han arriesgado a montar su propia empresa, presentando un elevado efecto demostrativo para las compañeras del mismo género (Esparcia \& Noguera Pitarch, 2000). En otras ocasiones, a lo que se contribuyó fue a sacar de la economía informal a mujeres trabajadoras y empresarias que ya poseían anteriormente un negocio, aunque no declarado. Por tanto, las actuaciones realizadas por emprendedoras presentaron una serie de cualidades positivas intangibles: por su condición sexual potenciadora del efecto demostrativo entre sus paisanas; por desarrollar su propio negocio, su propio proyecto de futuro; porque en muchas ocasiones ponen en valor determinados recursos endógenos, productos y servicios autóctonos.

Tampoco se debe olvidar que gracias, en parte, a los PDRs las mujeres jóvenes están realizando una relectura del medio rural. Gran parte de ellas han podido elegir ya su lugar, su identidad, accediendo a una oportunidad laboral y de negocio, e incluso, una participación real en las tareas de poder de estas comarcas, siendo modernas y de pueblo al mismo tiempo. Incluso en términos de género en relación con el empoderamiento de la mujer y de la gobernanza, especialmente, en los territorios del rural profundo y montano (Cassellas et al., 2013) en el que la progresiva y mayor educación y formación les está permitiendo asumir retos y proyectos innovadores en el contexto del mundo rural. Dicho de otro modo, "la postura que apoya que la educación y la formación fueron para las mujeres rurales un elemento de desarraigo y desapego del medio rural y, en definitiva, de abandono del mismo, ahora se revierte porque precisamente la educación y la formación se convierten en factores indispensables para construir las nuevas identidades rurales femeninas" (Porto et al., 2015, p. 403).

Pero a pesar de que las mujeres se están beneficiando de las actuaciones, lo hacen "aún en bastante menor medida que los hombres" (Calatrava, 2002, p. 75). En el mismo sentido apuntan los resultados obtenidos para la provincia de Granada (Navarro, Cejudo \& Maroto, 2014) y para toda Andalucía (Cejudo, Navarro y Camacho, en prensa), sobre todo si de mujeres jóvenes hablamos. Es más, en el diagnóstico que sobre la desigualdad de género realizó el Ministerio de Medio Ambiente, Rural y Marino (MARM, 2011, p. 245) señalaba que: "los resultados de cada 
uno de los capítulos temáticos (estructura demográfica crítica, posición de las mujeres en el nuevo modelo productivo, condiciones de vida y horizontes de cambio) han puesto de manifiesto que se mantienen profundas desigualdades en todos los aspectos contemplados, lo que afecta de manera muy especial a las condiciones de trabajo y expectativas personales de las mujeres". Ello no implica que su presencia como emprendedoras se vaya ampliando con el devenir del tiempo aunque variable en función de los diferentes territorios. Para el caso de Andalucía lideraron el 7,4 \% de los proyectos ejecutados, frente al 11,2 del varón, y la financiación media por cada uno de ellos fue casi 5000 euros menos para los de ellas; diferencias que se incrementan si añadimos la edad. Valores que distan mucho de los resultados de LEADER + para Cataluña, donde "las mujeres fueron responsables de algo más de la mitad de los proyectos promovidos individualmente" (Viladomiu et al., 2010, p. 181). Similares diferencias encontramos cuando de empleo generado y consolidado hablamos.

Las mujeres rurales sufren una doble discriminación, tanto por su género como por su lugar de residencia. De hecho, disponen de menores ofertas laborales allí que en la ciudad e, incluso, en muchas ocasiones son trabajadoras invisibles. "Un colectivo importante de mujeres que, aunque insertas en la economía productiva, son consideradas estadísticamente como inactivas debido a su inserción no formal" (Camarero \& Oliva, 2004, p. 160). Además, Sabaté (2009, p. 103) expresa rotundamente que "las políticas de desarrollo rural han incorporado de forma insuficiente la dimensión de género". Incluso, determinados yacimientos de empleo, tales como turismo, transformación artesanal de productos agroalimentarios, o cuidado de ancianos, promovidos por los PDRs, "se relacionan con actividades tradicionalmente asumidas por las mujeres en el ámbito doméstico. Siendo una oportunidad de profesionalización para las mujeres aunque presentan también un riesgo de reproducción de los roles de género tradicionales" (Sampedro, 2008, p. 91). Esta situación se agudiza en los municipios más pequeños, valga el caso de Castilla y León (Rico \& Gómez-Limón, 2011) y de los datos que para Andalucía se analizarán posteriormente.

En este contexto, las lecciones que nos enseñan los proyectos fallidos respecto a la participación de mujeres y jóvenes en estos Programas es que se refuerza la idea de que, de nuevo, son los jóvenes y las mujeres, sobre todo, jóvenes las que encuentran más dificultades para poder emprender. Son las que muestran ratios de proyectos fallidos/ejecutados más altas - no es así para el caso de la mujer de más de 35 años-, con valores que superan casi 10 puntos la media del conjunto de autónomos en el caso de la mujer joven y más de 7 puntos para el varón joven. Si de sociedades mercantiles hablamos, aquellas en las que más del $25 \%$ de sus socios son mujeres jóvenes, presentan unas ratios que casi duplican el valor medio de este tipo de sociedades $(38,8$ frente a 21). Es decir, el joven y especialmente si es mujer se enfrenta a una doble muralla que salvar frente al varón y mujer con más de 35 años; de un lado, conseguir que sus iniciativas puedan verse aprobadas $y$, de otro, que sean viables los pocos proyectos que se ejecutan con niveles de 
inversión inferiores en un 25,5\% a la media de los autónomos para el caso de los jóvenes y a un $37,8 \%$ si además es mujer. Entendemos que este hecho debe ser puesto en relación con el debate, creciente e intenso, relacionado con la justicia intergeneracional. El Estado del Bienestar puso, y aún lo sigue haciendo, su foco de atención financiera en la protección de los colectivos de más edad, convirtiéndose en lo que Myles (1984) denominó "Estados Providencia para la vejez", en perjuicio de nuevas necesidades de colectivos que se están incorporando a la vida adulta. Pero, son cada vez más los trabajos que evidencian, por un lado, el crecimiento de los niveles de pobreza en los colectivos de menor edad a la vez que se reducen los de la población de más de 65 años (OCDE, 2008); de otro, que los programas sociales, políticas familiares o políticas activas y pasivas de empleo se centran en los colectivos de mayor edad en diferentes países de la OCDE (Lynch, 2006) como es el nuestro; "en este contexto institucionalmente desfavorable, los jóvenes en España experimentan retrasos considerables en la edad de emancipación, dificultades para el acceso a la vivienda y suelen tener un número de hijos menor al que desean" (Marí-Klose, 2012, p. 71). Son, parafraseando el título del trabajo antes citado referido a los jóvenes, "prioridades poco prioritarias.

Atendiendo al ámbito (tipología de proyecto) el 68,38\% de las iniciativas fallidas (Tabla 5) se encuadran en el grupo de "Promoción de la adaptación y desarrollo de las zona rurales", lo cual tiene su lógica al ser el que ofrece, también, el mayor número de proyectos aprobados. Dentro de éste, y a nivel de subámbitos, los correspondientes a "servicios básicos para la economía y población rurales" así como la "diversificación de actividades agrícolas y próximas a ella, para crear actividades múltiples o ingresos adicionales" concentran prácticamente la totalidad de los proyectos fallidos. Tanto uno como otro suponen más del $25 \%$ de todos los registrados en la comunidad autónoma. Cifras también elevadas se registran en el ámbito de "ayuda a las PYME y a las empresas artesanales" con un $18 \%$ del total. 
Tabla 5. Proyectos Fallidos según tipo² (Ámbito) en los PDR de Andalucía (2002-2008)

\begin{tabular}{|l|r|r|r|r|r|r|}
\hline \multicolumn{1}{|c|}{ Ámbito } & Fallido & Ejecutado & Aprobado & Fall/Ejec & Fall/Apro & \multicolumn{1}{c|}{$\%$ Fall } \\
\hline 11 & 54 & 297 & 351 & 18,18 & 15,38 & 4,22 \\
\hline 12 & 1 & 6 & 7 & 16,67 & 14,29 & 0,08 \\
\hline 13 & 876 & 5669 & 6545 & 15,45 & 13,38 & 68,38 \\
\hline 1303 & 0 & 1 & 1 & 0,00 & 0,00 & 0,00 \\
\hline 1304 & 28 & 214 & 242 & 13,08 & 11,57 & 2,19 \\
\hline 1305 & 370 & 2374 & 2744 & 15,59 & 13,48 & 28,88 \\
\hline 1306 & 94 & 1223 & 1317 & 7,69 & 7,14 & 7,34 \\
\hline 1307 & 340 & 1618 & 1958 & 21,01 & 17,36 & 26,54 \\
\hline 1309 & 15 & 97 & 112 & 15,46 & 13,39 & 1,17 \\
\hline 1310 & 17 & 111 & 128 & 15,32 & 13,28 & 1,33 \\
\hline 1311 & 3 & 1 & 4 & 300,00 & 75,00 & 0,23 \\
\hline 1312 & 9 & 30 & 39 & 30,00 & 23,08 & 0,70 \\
\hline 16 & 241 & 1225 & 1466 & 19,67 & 16,44 & 18,81 \\
\hline 17 & 55 & 336 & 391 & 16,37 & 14,07 & 4,29 \\
\hline 21 & 4 & 13 & 17 & 30,77 & 23,53 & 0,31 \\
\hline 22 & 6 & 49 & 55 & 12,24 & 10,91 & 0,47 \\
\hline 23 & 4 & 156 & 160 & 2,56 & 2,50 & 0,31 \\
\hline 24 & 2 & 40 & 42 & 5,00 & 4,76 & 0,16 \\
\hline 25 & 4 & 16 & 20 & 25,00 & 20,00 & 0,31 \\
\hline 31 & 0 & 1 & 1 & 0,00 & 0,00 & 0,00 \\
\hline 32 & 6 & 80 & 86 & 7,50 & 6,98 & 0,47 \\
\hline 33 & 3 & 8 & 11 & 37,50 & 27,27 & 0,23 \\
\hline 35 & 9 & 79 & 88 & 11,39 & 10,23 & 0,70 \\
\hline 41 & 16 & 109 & 125 & 14,68 & 12,80 & 1,25 \\
\hline Gastos funcionamiento & 0 & 137 & 137 & 0,00 & 0,00 & 0,00 \\
\hline Total & 1281 & 8221 & 9502 & 15,58 & 13,48 & 100,00 \\
\hline
\end{tabular}

Fuente: elaboración propia a partir de la

Dirección General de Desarrollo Sostenible (2000-2008)

Si cruzamos las dos variables ya comentadas, los resultados se muestran en la Tabla 6.

2 El significado de las claves de ámbito es el siguiente. 11. Agricultura; 12 Aprovechamiento forestal; 13. Promoción de la adaptación y el desarrollo de las zonas rurales; 1304. Comercialización de productos agrícolas de calidad; 1305. Servicios básicos para la economía y población rurales; 1306. Renovación y desarrollo de pueblos y protección y conservación del patrimonio rural; 1307. Diversificación de actividades agrícolas y próximas a ella, para crear actividades múltiples o ingresos adicionales; 1309. Desarrollo y mejora de la infraestructura relacionada con el desarrollo de la agricultura; 1310. Incentivo de actividades turísticas; 1311. Incentivo de la artesanía en las explotaciones agrarias; 1312. Protección del medio ambiente en relación con el suelo, la silvicultura, la conservación del paisaje y el bienestar animal; 16. Ayudas a las PYME y a las empresas artesanales; 17. Turismo; 21. Políticas del mercado laboral; 22. Integración social; 23. Fomento de la educación y de la formación profesional no vinculadas a un sector específico (individuos, empresas); 24. Adaptabilidad, espíritu de empresa e innovación, tecnologías de la información y comunicación (individuos, empresas); 25. Medidas positivas a favor de las mujeres en el mercado laboral; 32. TIC, servicios y aplicaciones para ciudadanos y empresas; 33. Energías renovables; 35. Protección y restauración patrimonio natural y cultural; 41. Asistencia técnica y medidas innovadoras. 
Tabla 6. Proyectos Fallidos según Promotor y Ámbito en los PDR de Andalucía (2002-2008)

\begin{tabular}{|c|c|c|c|c|c|c|c|c|c|c|}
\hline \multirow{3}{*}{$\begin{array}{l}\text { ÁMBITO/, } \\
\text { PROMOTOR }\end{array}$} & \multicolumn{4}{|c|}{ AUTÓNOMOS } & \multicolumn{3}{|c|}{ SOCIEDADES MERCANTILES } & \multicolumn{2}{|c|}{ ENTIDADES PÚBLICAS } & \multirow{3}{*}{ TOTAL } \\
\hline & \multicolumn{2}{|c|}{ Maduros } & \multicolumn{2}{|c|}{ Jóvenes } & \multirow[b]{2}{*}{ MADURAS } & \multicolumn{2}{|c|}{ Jóvenes } & \multirow{2}{*}{$\begin{array}{c}\text { Corporación } \\
\text { Local }\end{array}$} & \multirow{2}{*}{$\begin{array}{c}\text { GAL o } \\
\text { Asociaciones }\end{array}$} & \\
\hline & Mujer & Hombre & Mujer & Hombre & & Mujer & Hombre & & & \\
\hline 11 & 4 & 7 & 1 & 2 & 19 & 5 & 0 & 4 & 2 & 54 \\
\hline 12 & & & & & & & & 1 & & 1 \\
\hline 13 & 86 & 133 & 32 & 53 & 142 & 34 & 14 & 142 & 95 & 876 \\
\hline 1304 & 1 & 5 & & & 4 & 1 & & 2 & 7 & 28 \\
\hline 1305 & 27 & 60 & 20 & 29 & 63 & 13 & 13 & 55 & 36 & 370 \\
\hline 1306 & 4 & 2 & & & 5 & & & 48 & 23 & 94 \\
\hline 1307 & 50 & 60 & 11 & 24 & 62 & 20 & 1 & 24 & 23 & 340 \\
\hline 1309 & 2 & 2 & & & 2 & & & 1 & 5 & 15 \\
\hline 1310 & 2 & 4 & 1 & & 5 & & & 4 & & 17 \\
\hline 1311 & & & & & 1 & & & & 1 & 3 \\
\hline 1312 & & & & & & & & 8 & & 9 \\
\hline 16 & 25 & 44 & 16 & 23 & 52 & 13 & 5 & 13 & 11 & 241 \\
\hline 17 & 13 & 3 & 3 & 2 & 6 & 3 & 0 & 5 & 5 & 55 \\
\hline 21 & & 2 & & & 1 & 1 & & & & 4 \\
\hline 22 & & & & & & & & 4 & 2 & 6 \\
\hline 23 & & & & & & & & 2 & 2 & 4 \\
\hline 24 & & & & & & & & & & 2 \\
\hline 25 & & & & & & & & 3 & & 4 \\
\hline 32 & 0 & 0 & 0 & 0 & 0 & 0 & 0 & 6 & 0 & 6 \\
\hline 33 & & 1 & & & & & & 2 & & 3 \\
\hline 35 & 1 & 0 & 0 & 0 & 0 & 0 & 0 & 6 & 2 & 9 \\
\hline 41 & 0 & 2 & 0 & 0 & 3 & 1 & 0 & 1 & 7 & 16 \\
\hline Total & 129 & 192 & 52 & 80 & 223 & 57 & 19 & 188 & 126 & 1.281 \\
\hline
\end{tabular}

Nota: Para la significación de las claves, ver nota de la Tabla 5.

Fuente: elaboración propia a partir de la

Dirección General de Desarrollo Sostenible (2000-2008)

Sus datos confirman algunas cuestiones ya señaladas e introducen importantes matices en otras. De un lado, se comprueba que la mayor parte de los proyectos fallidos que se producen en los ámbitos 1305 y 1307 vienen de la mano de promotores privados, ya sean autónomos o empresas mercantiles, teniendo también una representación significativa los públicos. Ahora bien, estos últimos destacan respecto de los primeros en la importancia que adquieren los proyectos fallidos relacionados con la renovación de los pueblos y la conservación del patrimonio rural (1306), aspecto éste especialmente relevante para el caso de las corporaciones locales y muy significativo para el caso de los GAL. Es decir, se trata de iniciativas con una clara orientación de servicio público, poco atractivas para el sector privado y que, frecuentemente, requieren de un alto volumen de inversión que difícilmente se puede asumir desde los exiguos presupuestos municipales, especialmente si del rural profundo hablamos. Pero además, algo que diferencia a las corporaciones locales de los GAL es la significativa importancia que adquiere un conjunto de proyectos fallidos comprendidos entre las claves 21 y 35 ya que de sus 38 fallidos, en 23 de ellos sus promotores fueron corporaciones locales. Son actuaciones ligadas a la formación, a la puesta en marcha de medidas en favor de la mujer, al mercado laboral, etc. En definitiva, los ayuntamientos, como otro agente más del territorio, acometen, ante la ausencia de iniciativa 
privada, lícitamente, proyectos de interés social para cubrir necesidades colectivas locales que sus exiguos presupuestos impiden (Alario \& Baraja, 2006, pp. 290-291).

Si de los promotores privados hablamos, es evidente que la mujer presenta un alto nivel de fallidos en el ámbito de los servicios básicos para la economía rural (1305) sobre todo para el caso de la mujer joven con un $38,5 \%$ de sus fallidos, lo que supone casi 10 puntos más que el valor medio para este ámbito. Pero es más, 13 de los 19 proyectos fallidos de las sociedades mercantiles de jóvenes mujeres proceden de dicho ámbito, lo que supone el 68,4\% de los aprobados. En el caso de este colectivo joven femenino los niveles de fracaso en el ámbito 16 (PYMES y artesanía) también superan con mucha claridad los de los otros promotores con un 30,8 \%, 12 puntos más que la media del ámbito.

Otro hecho a destacar es la importancia que adquiere para la mujer de más de 35 años los intentos frustrados en relación con la puesta en marcha de proyectos ligados a dos ámbitos, en cierto modo relacionados, como son la diversificación de las actividades agrícolas para la generación de rentas adicionales (1307) y el turismo (17). Esta apuesta debe ser entendida como en el contexto de la unidad familiar de la que forma parte en la que el trabajo en el sector agrario es desarrollada por el marido, lo que le permite, a la vez, una cobertura financiera, a veces imprescindible, para afrontar el riesgo de invertir en este tipo de proyectos. Las mujeres fueron pioneras en la implantación de casas y hoteles rurales, y ello a pesar de que encontraron serias dificultades de financiación y apoyo familiar. Ahora bien, no conviene olvidar que en otros casos las involucradas no eran esposas de agricultores, por lo que el turismo no funcionó como una actividad complementaria de la explotación familiar (Navarro, Cejudo \& Maroto, 2014). Además, y como se ha demostrado en estudios similares (Sparrer, 2003), en gran parte de los casos se trataba de "empresarias ficticias", que aparecían como emprendedoras por razones fiscales; es decir, que aunque la mujer figuraba como propietaria, no desempeñaba las funciones de gerente, quedando su función relegada a las labores domésticas tradicionales: preparar las comidas y cenas, limpieza, lavar y planchar, etcétera.

En el caso de las sociedades mercantiles destacamos dos hechos. De un lado, que, después de la mujer, es el promotor que presenta mayores niveles de fracaso en el ámbito 1307 (diversificación de las actividades agrarias) con un 35,1\% así como, de otro, el de liderar los fallidos en el ámbito 11, el referido a la agricultura. No en vano, de los 54 proyectos no ejecutados dentro de esta categoría 19 pertenecen a sociedades mercantiles y otros 5 a sociedades mercantiles jóvenes varones, lo que supone casi la mitad de los fallidos de esta categoría.

\subsection{La distribución territorial de los proyectos fallidos por Grupos de Acción Local}

La incidencia de los proyectos fallidos a nivel de Grupo de Desarrollo Rural permite matizar algunas de las conclusiones generales anteriores, pues su repercusión territorial ha sido muy variable y condicionada por múltiples factores. 


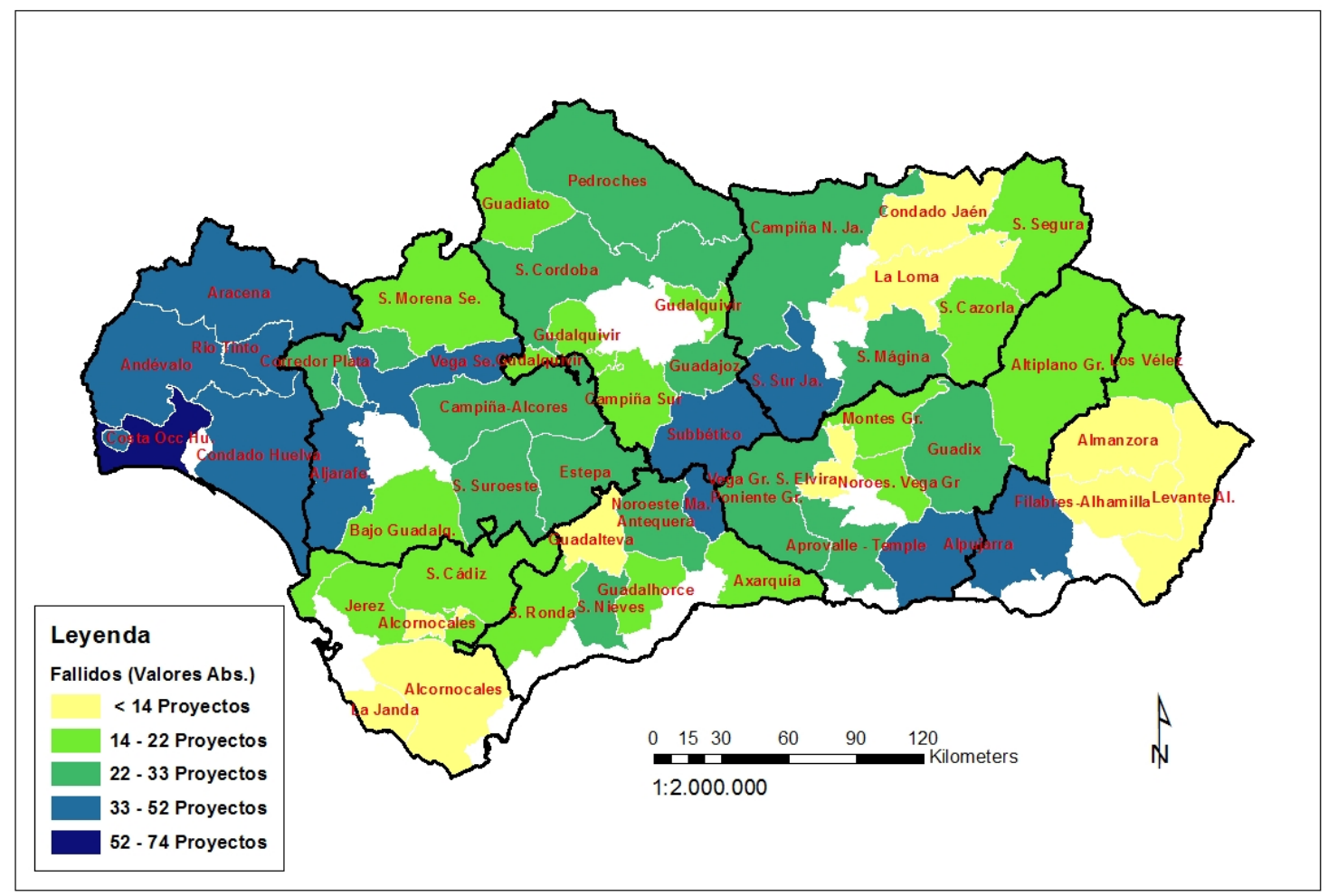

Fuente: elaboración propia a partir de la

Dirección General de Desarrollo Sostenible (2000-2008)

Si nos atenemos a los valores absolutos se constata un mayor número de proyectos fallidos (Figura 1) en los GAL correspondientes a la provincia de Huelva (Costa Occidental, Andévalo, Cuenca Minera, Condado de Huelva o Aracena) y Sevilla (Aljarafe-Doñana, Gran Vega de Sevilla). También se observa una mayor presencia en los GAL centrales, de las provincias de Jaén, Málaga y Córdoba (Sierra Sur de Jaén, Subbética Cordobesa y Territorio Nororiental de Málaga) y en la Alpujarra de Almería-Granada.

Datos que se ven ligeramente matizados si se ponderan en relación con los proyectos totales aprobados. Nuevamente se aprecia una cierta concentración de proyectos fallidos en los GAL de la provincia Huelva - con un 29,02 \% en la Costa Occidental y un 21,11\% en el Condado- y Sevilla -tienen cifras elevadas la Gran Vega con un 28,08\% y el Corredor de la Plata-. En Córdoba destaca también la comarca del Subbético.

De igual modo (Figura 2) no se observa una especial presencia de proyectos fallidos en los GAL orientales de Andalucía, los que tenían menor dinamismo. Los proyectos fallidos se concentrarán en aquellos Grupos de Acción Local con mayor volumen de inversión y de proyectos (Cejudo \& Navarro, 2012). 


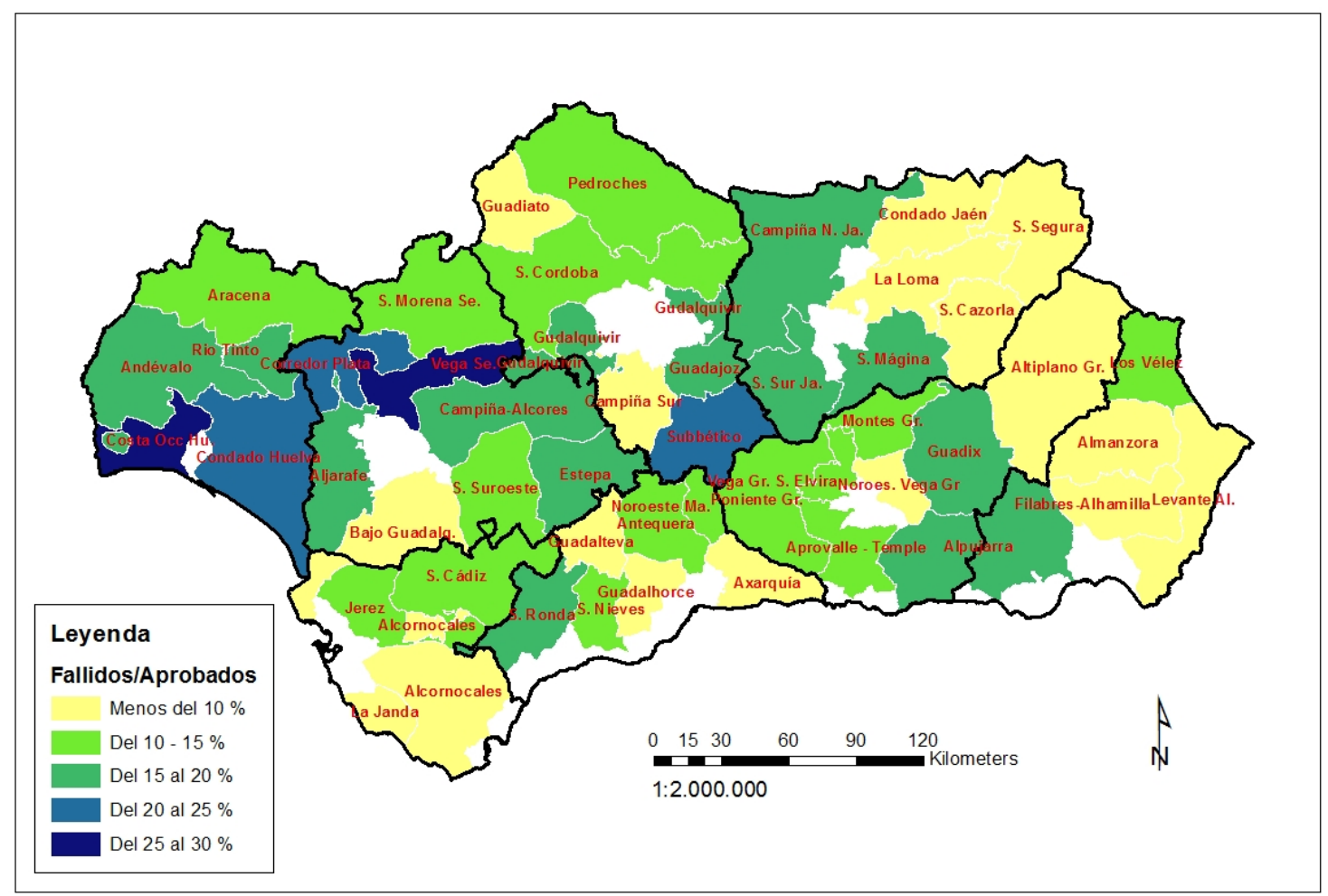

Fuente: elaboración propia a partir de la

Dirección General de Desarrollo Sostenible (2000-2008)

Estos datos parecen confirmar la hipótesis de que son los Grupos de Acción Local más dinámicos, donde existe un tejido empresarial previo, los que registraran, también, los niveles de proyectos fallidos más significativos. Tal y como se puede comprobar en la Figura 3, la inversión privada ha sido más elevada en los grupos de las provincias occidentales de Andalucía, con especial incidencia en las de Sevilla y el sector costero de Huelva, además del Sur y Norte de Córdoba. Situación que a su vez, es reflejo de lo lo desequilibrada que es la región en los aspectos económicos, donde unas cuantas y escasas comarcas dotadas de los mayores niveles de desarrollo económico, imponen valores medios muy altos en cualquiera de los indicadores que se utilicen, e imposibilitan que las restantes comarcas de Andalucía se acerquen mínimamente a los mismos. Conclusiones que ya se ponían de manifiesto en el Informe Territorial de Andalucía del año 2010 (Pita \& Pedregal, 2011). 


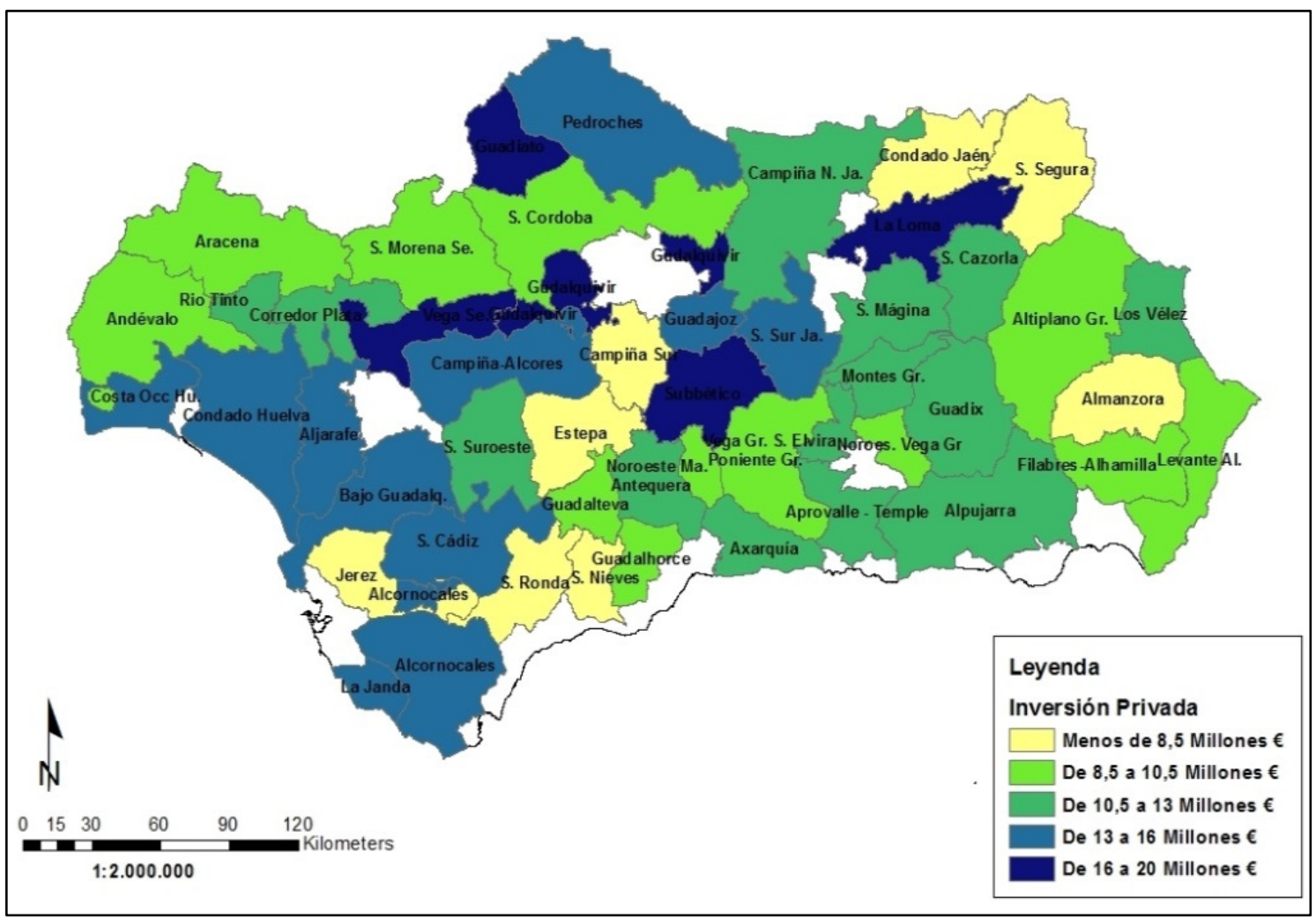

Fuente: elaboración propia a partir de la

Dirección General de Desarrollo Sostenible (2000-2008)

\subsection{Los proyectos fallidos a nivel municipal}

En primer lugar, debemos aclarar que los proyectos que se estudian a partir de este apartado son sólo aquellos que se iban a desarrollar dentro de un sólo municipio, descartándose los demás, por lo que el número total de dichos proyectos de reducen a 1206.

Atendiendo al tamaño demográfico (Tabla 7) se constata como la mayor parte de los proyectos fallidos se concentra en municipios situados en el rango de 2000 a 4999 habitantes (el 27,3\%) seguidos de los que están comprendidos entre los 5000 y 9999 habitantes (21,8\%). Valores que se corresponden, también con los tamaños municipales que concentran la mayoría de los proyectos aprobados $(29,4 \%$ y $21,8 \%$ respectivamente). Otra cuestión que nos parece trascendente es el señalar que los municipios de tienen, al menos, 1 proyecto fallido y menos de 2000 habitantes son casi el $30 \%$ del total y acaparan casi el $17 \%$ de los fallidos. Si tenemos en cuenta el número absoluto de proyectos y el número de municipios en estos intervalos de población, rápidamente se intuye, como luego veremos, que en aquéllos con menor población los escasos proyectos, cuando los hubo, aprobados terminaron sin ejecutarse en un sinfín de casos. 
Tabla 7. Proyectos Fallidos según tamaño municipal en los PDR de Andalucía (2002-2008)

\begin{tabular}{|c|c|c|c|c|c|c|c|c|c|c|}
\hline \multirow{3}{*}{$\begin{array}{l}\text { Intervalos de } \\
\text { Población }\end{array}$} & \multicolumn{4}{|c|}{ Fallidos } & \multicolumn{4}{|c|}{ Ejecutados } & \multirow{2}{*}{\multicolumn{2}{|c|}{ Total Aprobados }} \\
\hline & \multicolumn{2}{|c|}{$\mathrm{N}^{\circ}$. Municipios } & \multicolumn{2}{|c|}{$\mathrm{N}^{\circ}$. Proyectos } & \multicolumn{2}{|c|}{$\mathrm{N}^{\circ}$. Municipios } & \multicolumn{2}{|c|}{$N^{\circ}$. Proyectos } & & \\
\hline & Abs. & Rel. (\%) & Abs. & Rel. (\%) & Abs. & Rel. (\%) & Abs. & Rel. (\%) & Abs. & Rel. (\%) \\
\hline $0-499$ & 21 & 4,9 & 25 & 2,1 & 74 & 11,2 & 175 & 2,6 & 200 & 2,5 \\
\hline 500-999 & 41 & 9,6 & 64 & 5,3 & 79 & 12,0 & 291 & 4,3 & 355 & 4,4 \\
\hline 1000-1999 & 65 & 15,2 & 113 & 9,4 & 111 & 16,8 & 664 & 9,8 & 777 & 9,7 \\
\hline $2000-4999$ & 131 & 30,7 & 329 & 27,3 & 194 & 29,3 & 1995 & 29,4 & 2324 & 29,1 \\
\hline 5000-9999 & 78 & 18,3 & 263 & 21,8 & 100 & 15,1 & 1479 & 21,8 & 1742 & 21,8 \\
\hline $10000-19999$ & 55 & 12,9 & 220 & 18,2 & 59 & 8,9 & 1027 & 15,1 & 1247 & 15,6 \\
\hline $20000 y+$ & 36 & 8,4 & 192 & 15,9 & 44 & 6,7 & 1155 & 17,0 & 1347 & 16,9 \\
\hline Total & 427 & 100,0 & 1206 & 100,0 & 661 & 100,0 & 6786 & 100,0 & 7992 & 100,0 \\
\hline
\end{tabular}

Fuente: elaboración propia a partir de la

Dirección General de Desarrollo Sostenible (2000-2008)

El análisis espacial de los proyectos fallidos a nivel municipal, permite apreciar las diferencias internas entre los diferentes Grupos de Acción Local (Figura 4), y el peso que en los resultados globales tienen el comportamiento de algunos municipios.

Figura 4. Proyectos Fallidos/Proyectos Aprobados.

Municipios. Valores Relativos. Andalucía (2002-2008)

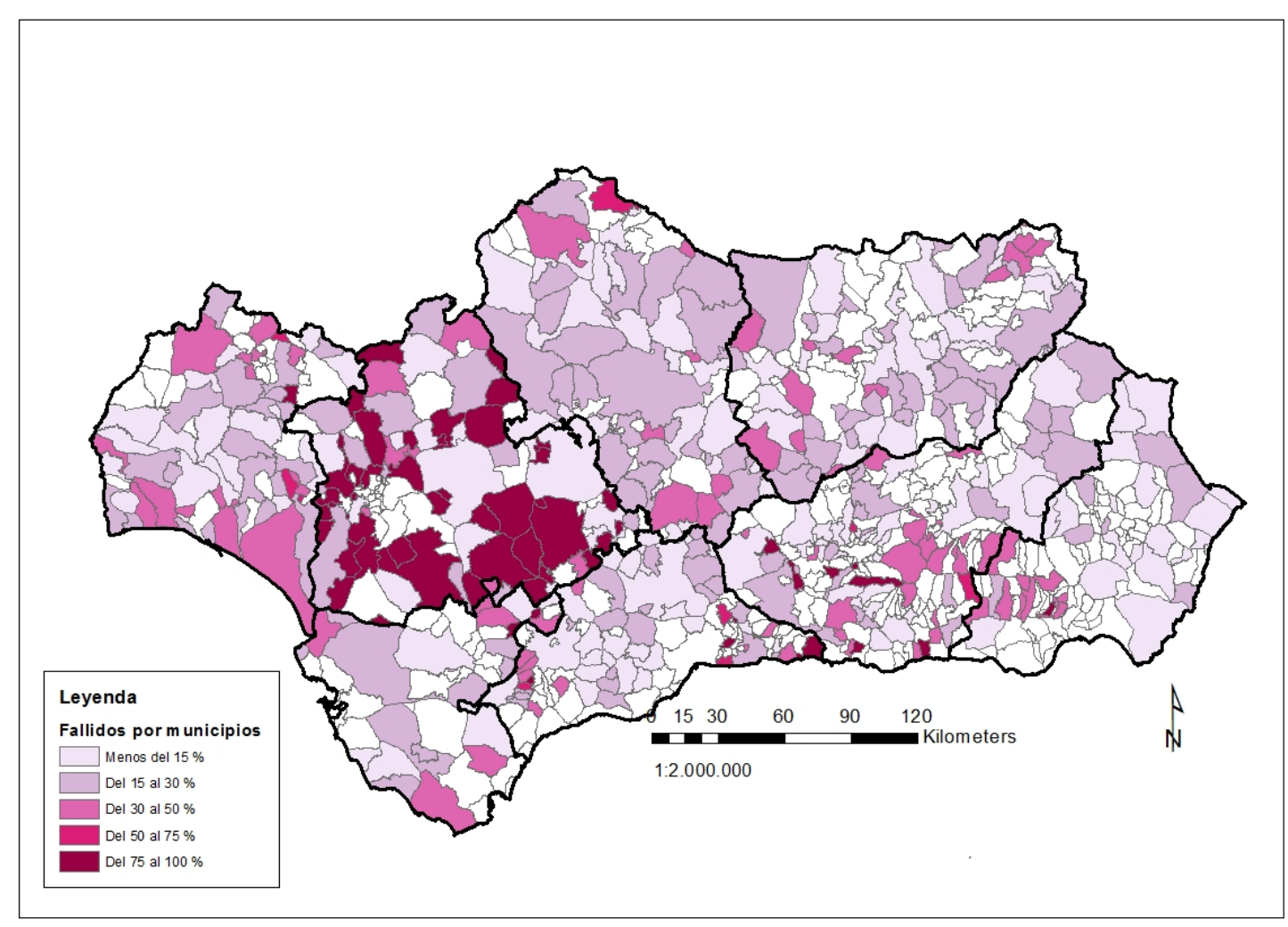

Fuente: elaboración propia a partir de la

Dirección General de Desarrollo Sostenible (2000-2008)

Espacialmente se constata el mayor peso de los proyectos fallidos en los municipios andaluces occidentales, y particularmente los localizados en la provincia de Sevilla, que llegan a superar en 
algunas entidades el $75 \%$ del total. Conviene volver a recordar en este sentido que son estos municipios los que registran también el mayor número de proyectos exitosos (culminados) y donde la cuantía de la inversión comprometida -suma de inversión privada y subvención- es mayor.

La distribución espacial de los proyectos fallidos puede inducir en un primer análisis a conclusiones erróneas sobre los efectos territoriales de los proyectos de desarrollo rural, pues si bien es cierto que su incidencia es menor en los municipios orientales, también lo es que es en este sector de Andalucía donde el peso de la iniciativa privada se reduce considerablemente y donde la promoción de proyectos desde instancias públicas es mayor, sustentados en gran parte en las subvenciones, con escasa aportación de la inversión privada. De esa forma el "supuesto éxito" de los proyectos no hace más que reincidir en el desigual desarrollo territorial y los efectos desequilibradores de las políticas llevadas a cabo. Los proyectos con mayores cantidades subvencionadas, se destinan en gran medida a la dinamización y divulgación de actividades, con una fuerte presencia de diversos Centros de Interpretación o de Innovación de cada uno de los territorios. Asumiendo, como señalan Arcilla y López (2015, pp. 161-162), que su distribución geográfica no ha sido la adecuada, con una planificación territorial, de gestión y mantenimiento, en muchos casos, errónea o inexistente fruto, demasiadas veces, de una sobrevaloración de su potencial turístico.

Pero es más, incluso en este sector oriental, los municipios asentados en zonas de montaña como pueden ser la Alpujarra Granadina y Almeriense, Sierra de Segura en Jaén, o el Subbético de Córdoba, junto con Sierra Morena, son los que presentan porcentajes de fallidos más elevados en comparación con los valores medios de su entorno (Figura 4).

Imagen muy distinta se obtiene si el análisis se centra en el registro de la concentración de proyectos fallidos a nivel municipal (Figura 5). En este caso al realizarse el cómputo por los valores absolutos, la incidencia de los tamaños demográficos de los municipios es evidente. No es de extrañar en consecuencia que los valores máximos se registren en Jerez de la Frontera, y que en general entre los 50 municipios con más proyectos fallidos sean mayoritarias entidades de población del sector occidental de Andalucía (provincias de Huelva, Sevilla, Córdoba), donde la presencia de municipios de tamaño medio es más importante. Aparecen así destacadas entidades como Ayamonte, Lepe, Punta Umbria, Aracena, Valverde del Camino, Lora del Río, Carmona, Utrera, Montoro, Lucena o Loja. La presencia de los municipios orientales es mínima, sólo algo más elevada en el caso de Málaga y reducida a algunas de las cabeceras comarcales en los casos de Granada, Jaén y Almería.

A la hora de evaluar la eficiencia de los Proyectos de Desarrollo Rural una línea clara es a través de los efectos positivos de estas iniciativas en indicadores como el incremento del empleo o la renta por habitante entre otros. Pero en situaciones territoriales tan complejas como la andaluza los 
"vacíos de gestión", es decir donde no se ha hecho nada o donde las políticas públicas no han sido capaces de llevar a término proyectos iniciados, constituye también un indicador de primer orden para realizar dicha evaluación.

Figura 5. Top 50 municipios con más proyectos fallidos

Valores Absolutos. Andalucía (2002-2008)

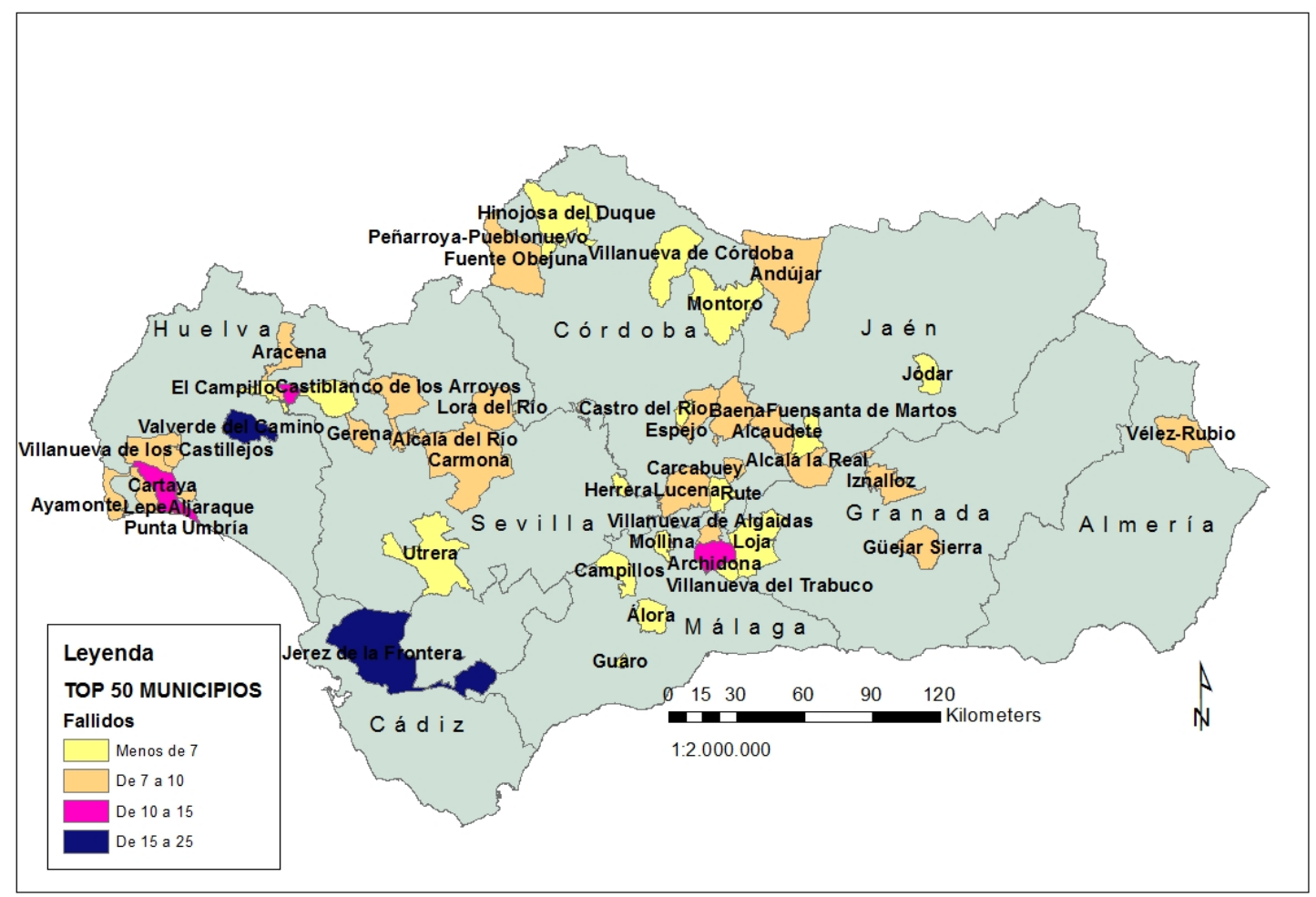

Fuente: elaboración propia a partir de la

Dirección General de Desarrollo Sostenible (2000-2008)

Las dos figuras siguientes ofrecen la expresión territorial, a nivel municipal, de lo que podríamos llamar la "cara amarga del desarrollo territorial andaluz". De un lado los municipios en los que la totalidad de los proyectos aprobados han resultados fallidos ya que ninguno se ha ejecutado con subvención de estos Programas (Figura 6), y de otro aquellos municipios en los que la inversión ha sido tan escasa o no se ha llevado a cabo ninguna, que también se puede considerar como una política territorial "fallida".

En lo referente a los municipios en los que ninguno de los Proyectos Aprobados se lleva a cabo (todos fallidos) la concentración de los mismos en los municipios de la provincia de Sevilla es no solo evidente con 39 casos sobre un total de 53, sino también por el volumen de proyectos iniciados -frecuentemente entre 4 y 8 proyectos- a nivel municipal. Aunque a una distancia considerable y con iniciativas de 1 o 2 proyectos municipales le siguen entidades de la provincia de Granada. 
Figura 6. Municipios con todos los proyectos aprobados fallidos.

Valores absolutos. Andalucía (2002-2008)

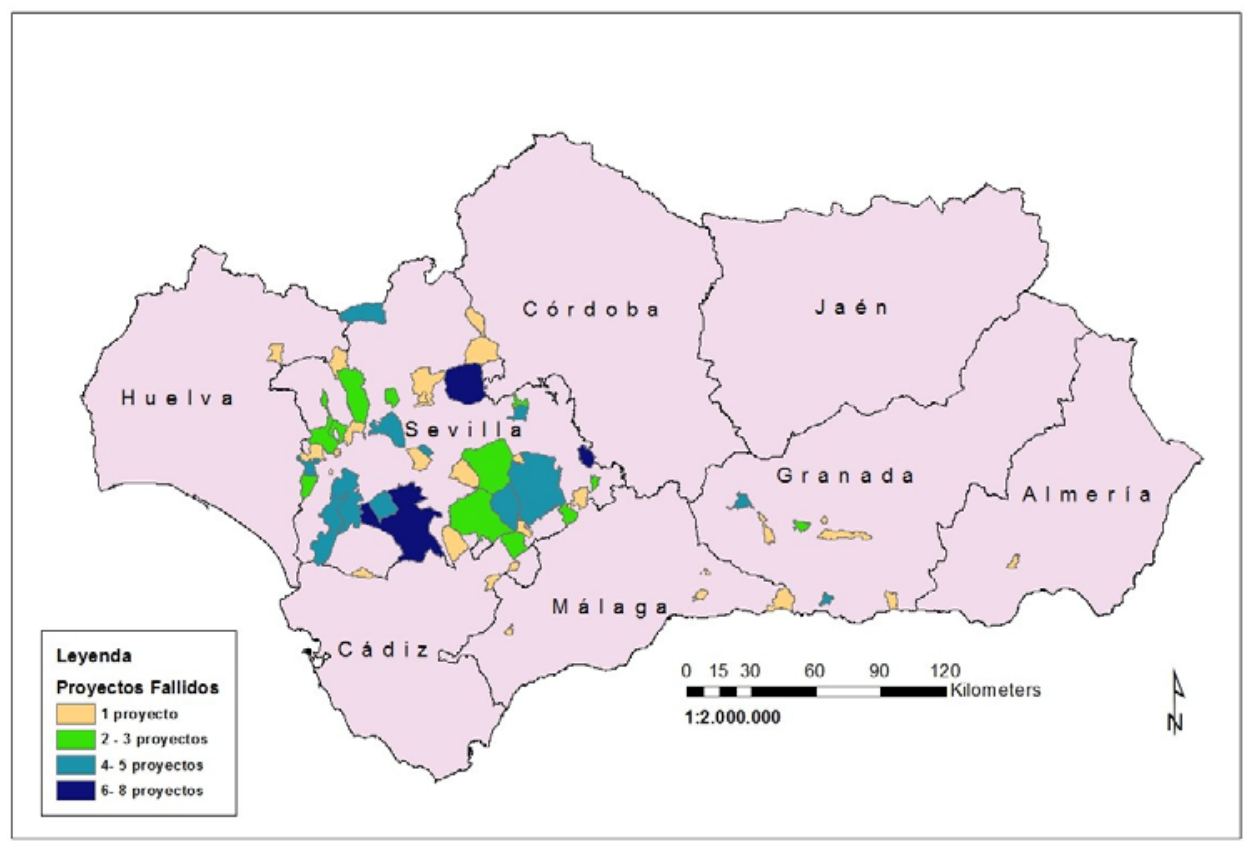

Fuente: elaboración propia a partir de la

Dirección General de Desarrollo Sostenible (2000-2008)

Figura 7. Top 50 municipios con menor inversión en PRD y municipios sin inversión.

Valores absolutos. Andalucía (2002-2008)

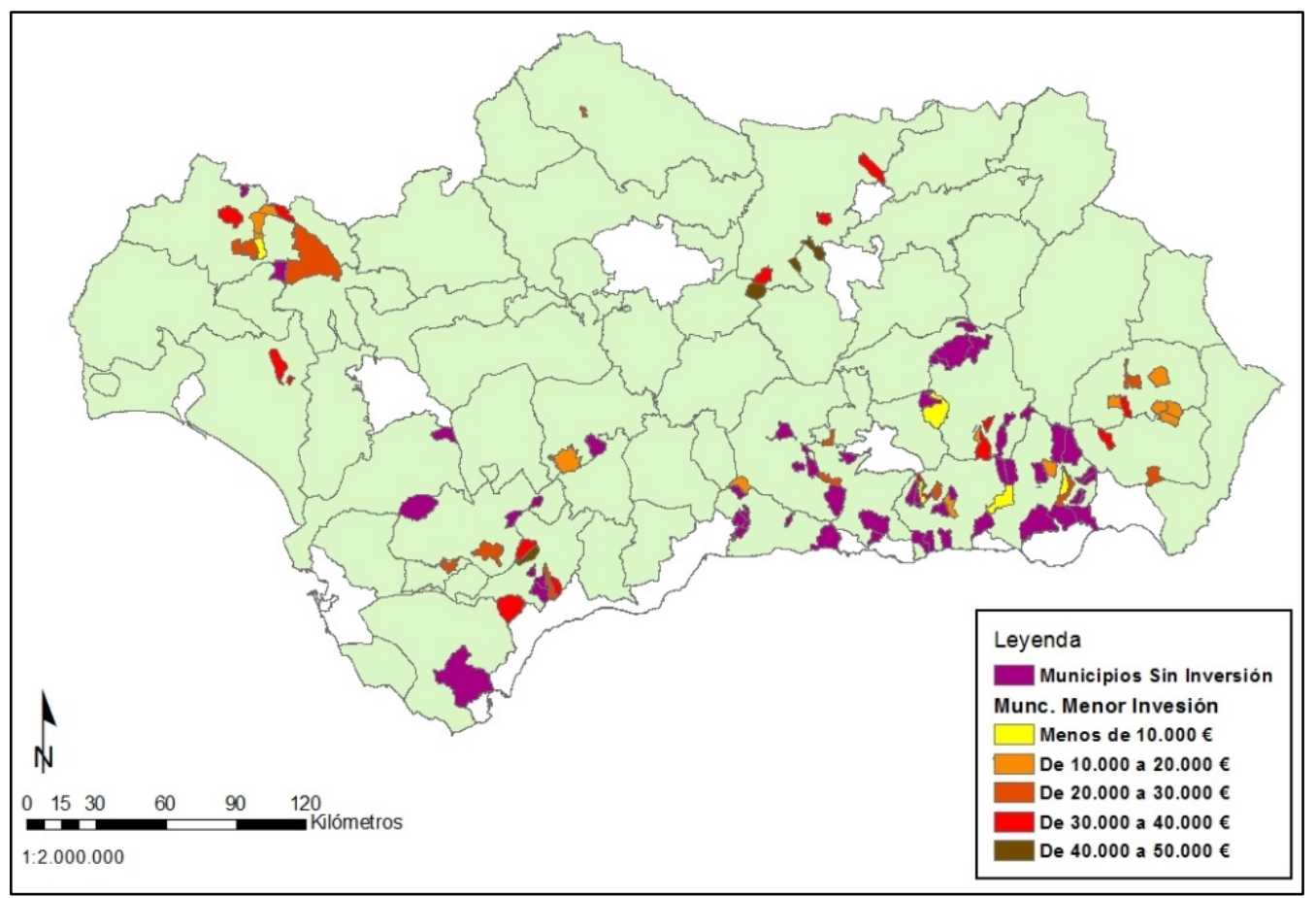

Fuente: elaboración propia a partir de la Dirección General de Desarrollo Sostenible (2000-2008) 
Las Figuras 6 y 7 resultan complementarias. Si en la primera se reflejan los municipios con todos los proyectos fallidos, es decir no se ha llevado a cabo ninguno a pesar de haberse iniciado su tramitación, en la segunda se encuentran los municipios en los que ni siguiera se llegó a dicha fase. Son municipios sin ningún proyecto, y al igual que en el caso anterior, que han quedado fuera de los Programas de Desarrollo Rural.

Ahora bien, tal y como se puede comprobar, la distribución espacial de ambos fenómenos es bien distinta. En el primero de los casos - proyectos iniciados pero sin terminar-, la concentración en el sector occidental es evidente (aspecto ya señalado) mientras en el segundo los municipios sin proyectos se encuentran básicamente en las provincias de Granada y Málaga. El mayor dinamismo de las provincias occidentales genera no sólo un número mayor de proyectos ejecutados, sino también de fracasos (fallidos), proyectos incipientes y poco maduros que se inician con el atractivo de captar la subvención, pero incapaces de cumplir los requisitos administrativos. En las provincias orientales será la ausencia emprendedores, de capital social capaz de liderar masivamente las iniciativas, el que limite el acceso a las subvenciones y en consecuencia ni siquiera presente proyectos. No hay que olvidar en este sentido lo raquítico que es el tejido empresarial de muchos de los municipios orientales, así como su elevado grado de envejecimiento o reducido peso demográfico.

Esta información se ha complementado con los municipios con menor inversión en el conjunto del periodo de programación. Los resultados están ahí, son evidentes con una concentración en municipios de montaña. Como bien señala Piła y Pedregal (2015, p. 52) en relación con la cohesión territorial de Andalucía, "los mayores problemas se derivan de la falta de equidad que caracteriza a determinados indicadores y variables, especialmente los de carácter económico y, más particularmente, los asociados a la competitividad. Esta es una magnitud en la que existen desequilibrios potentes en la región, una concentración de las actividades competitivas en muy escasos núcleos. Esto constituye un hecho importante a tener en cuenta en el diseño de las políticas de integración y convergencia económica".

No estamos afirmando que exista una relación causa-efecto entre distancia y grado de desarrollo económico, aunque en el caso de las regiones NUT3 de la UE-15 se ha demostrado que existe una relación inversa entre ellos "estadísticamente significativa" (Copus, 2008: 53), sino que en estos territorios, a la hora de explicar dichos procesos, confluyen factores que Copus denomina como "perificidad espacial" y otros "perificidad no espacial" entre los que destacan la escasa significación de capital social (Tellmann, 2012; Esparcia, Escribano \& Buciega, 2015; Foronda, 2015), la dinámica creciente de acumulación de capital como el elemento central para el crecimiento de las economías de mercado (Piketty, 2014; Currie-Alder, 2016) o el desarrollo desigual entendido como como producto y premisa del desarrollo capitalista; producto concretado y visualizado, manifiestamente, entre los espacios desarrollados y subdesarrollados, entre regiones 
en auge y en declive, barrios en expansión frente a suburbios urbanos (Copus et al., 2015), así como premisa en la medida en que éste sólo puede ser entendido por medio de un análisis teórico de la producción capitalista de la naturaleza y del espacio (Harvey, 2006; Smith \& Harvey, 2008).

Cada día es más evidente que la Política de Desarrollo Rural europea después de 2020 debe reforzar, entre otras cuestiones, su enfoque "basado en el lugar" aumentado la relevancia de los contextos reales en la selección de sus prioridades estratégicas así como poner el foco en la dimensión territorial de la distribución de sus fondos. Elemento esencial para hacer frente a los desafíos específicos de cada región, especialmente, en territorios rurales con fuerte riesgo de marginación y pobreza que afectan, fundamentalmente, a los "nuevos" Estados miembro, a numerosas regiones de los países mediterráneos así como a regiones remotas de otros países de la UE (Dax \& Copus, 2016).

\section{Conclusiones}

La eficiencia de los Programas de Desarrollo Rural y sus repercusiones territoriales se evalúa principalmente a través de los proyectos ejecutados, analizando las inversiones totales así como las subvenciones. A partir de aquí se puede, si la información disponible lo permite, descender a nivel municipal valorando los ámbitos y los destinatarios. Esta es una línea de investigación que hemos realizado en otras ocasiones (Navarro, Cejudo \& Maroto, 2014; Cejudo \& Navarro, 2009) junto con otros autores en otros ámbitos (Böcher, 2008; Bosworth, 2015). El análisis de los Proyectos Fallidos que se propone en este documento supone un acercamiento diferente al estudio de los Programas de Desarrollo Rural que permite acotar, aún más, los desequilibrios territoriales que se han acentuado a través de estos programas. A su vez, es una línea de investigación que abre interesantes posibilidades a la hora de evaluar cómo se ha realizado la gestión de estos Programas, y aprender de los errores cometidos.

A nivel del total de Andalucía el análisis de este periodo de Programas de Desarrollo Rural muestra una incidencia relativamente baja de los proyectos fallidos pues suponen un $13,5 \%$ de los inicialmente aprobados. Sin embargo estas cifras esconden situaciones territoriales muy diferentes como se ha tenido ocasión de constatar a través de la cartografía presentada. El análisis espacial, a través de la cartografía, se erige en herramienta esencial para la evaluación de las repercusiones que los Programas de Desarrollo Rural en territorios amplios y complejos como la comunidad autónoma de Andalucía.

Los datos disponibles a distintas escalas -autonómica, de grupo de desarrollo rural y municipalpermite apreciar comportamientos que, cuanto menos, nos deben hacer pensar en una gestión francamente mejorable en muchos de los grupos y en una necesaria modificación de los criterios por los que se aprueban los proyectos o son objeto de renuncia-rescisión del contrato. 
A la hora de valorar los resultados debe destacarse como han sido los grupos sociales más necesitados de las subvenciones los que muestran una mayor presencia de proyectos fallidos. Nos referimos a los jóvenes, a los autónomos que promueven proyectos propios, y a las mujeres. En cuanto a los ámbitos o líneas de inversión con mayor porcentaje de fallidos, se observa una mayor incidencia en aquellos con pocos proyectos presentados, y en cierta medida de solicitud poco frecuente. Proyectos que sin embargo, podrían tener un carácter innovador y demostrativo. .

Muchas son las interrogantes que se abren con el análisis de los proyectos de desarrollo fallidos, pero de un modo especial cuando se desciende a nivel de grupo de desarrollo o de municipio. En un sector importante de Andalucía la totalidad de los proyectos municipales aprobados son fallidos. Es decir no se ha ejecutado ninguno aun teniendo subvenciones comprometidas. Datos que quedan enmascarados a nivel de grupo en numerosas ocasiones. También es de destacar que amplios sectores de la comunidad autónoma, municipios pequeños, frecuentemente por debajo de los 2000 habitantes y rentas escasas, localizados en zonas de montaña en los que la actividad agraria cada vez genera menos empleo, han quedado fuera de estos programas, al no haberse aprobado ningún proyecto.

Agradecimientos: Este trabajo se ha realizado en el marco del proyecto de investigación "Programas de desarrollo y cambio rural en la Unión Europea: gobernanza, resultados y lecciones a compartir 2007-2013" financiado por el Ministerio de Economía y Competitividad español dentro de su Programa de Excelencia, CSO2014-56223-P. Agradecer también la disposición de los equipos técnicos y gerencia de los Grupos de Acción Local de Alfanevada, Alpujarras, Guadix, Poniente Granadino, Valle de Lecrín-Temple y Vega-Sierra Elvira

Declaración responsable: Las/os autoras/es declaran que no existe ningún conflicto de interés en relación a la publicación de este artículo. Los autores del presente artículo han colaborado de forma conjunta en las distintas fases del mismo por lo que no es posible diferenciarlas, a excepción de la maquetación final de la cartografía que ha sido realizada por José Antonio Cañete Pérez. 


\section{Bibliografía}

Alario, M., \& Baraja, E. (2006). Políticas públicas de desarrollo rural en Castilla y León, ¿sostenibilidad consciente o falta de opciones? LEADER II. Boletín de la Asociación de Geógrafos Españoles, 41, 267-293.

Alonso, P., \& Macias, A. (2014). Neoliberalismo corporativo y clientelismo en España: Etnografía de la financiación europea del desarrollo rural a través de un proyecto fallido. Revista de Antropología Iberoamericana, 9(3), 223-250. doi: http://dx.doi.org/10.11156/Aibr.090302

Arcila, M., \& López, J. A. (2015). Los centros de interpretación como motor de desarrollo turístico local, ¿un modelo fracasado? El caso de la provincia de Cádiz. Boletín de la Asociación de Geógrafos Españoles, 67, 143-165.

Augustyn, A., \& Nemes, G. (2014). Catching up with the West? Europeanisation of rural policies in Hungary and Poland. Studies in agricultural economies, 116, 114-121. doi: http://dx.doi.org/10.7896/j.1419

Böcher, M. (2008). Regional governance and rural development in Germany: the implementation of LEADER +. Sociologia Ruralis, 48(4), 372-388. doi: http://dx.doi.org/10.1111/j.1467$\underline{9523.2008 .00468 . x}$

Bosworth, G., Annibal, I., Price, L., Sellick, J., \& Shepherd, J. (2015). Empowering local action through neo-endogenous development; the case of LEADER in England. Sociologia Ruralis, 56(3), 427-449. doi: http://dx.doi.org/10.1111/soru.12089

Buciega, A. (2012). Capital social y LEADER. Los recursos generados entre 1996 y 2006. Ager, 12, 111-144. doi: http://dx.doi.org/10.4422/ager.2012.02

Cachón, L. (2009). La "España inmigrante": marco discriminatorio, mercado de trabajo y políticas de integración. Barcelona: Anthropos.

Calatrava, J. (2002). Mujer y desarrollo rural en la globalización: de los proyectos asistenciales a la planificación de género. Información Comercial Española, 803, 73-90. doi: http://dx.doi.org/

Camarero, L. (Coord.) (2009). La población rural de España. De los desequilibrios a la sostenibilidad social. Barcelona: La Caixa.

Camarero, L., \& Oliva, J. (2004). Las trabajadoras invisibles de las áreas rurales: un ejercicio estadístico de estimación. Empiria, 7, 159-179. doi: http://dx.doi.org/10.5944/empiria

Casellas, A., Tulla, A. F., Vera, A., \& Pallarès Blanch, M. (2013). Gobernanza local y espacio rural: un análisis territorial desde la perspectiva de género. Boletín de la Asociación de Geógrafos Españoles, 62, 379-402. 
Cejudo, E., \& Navarro, F. (2003). El reparto territorial de los programas de desarrollo rural. El caso de la provincia de Granada. Anales de Geografía, 23, 131-162.

Cejudo, E., \& Navarro, F. (2009). La inversión en los programas de desarrollo rural. Su reparto en la provincia de Granada. Anales de Geografía, 29(2), 37-64.

Cejudo, E., \& Navarro, F. (2012). Quince años de aplicación de los Programas de Desarrollo Rural. Desigualdades sociales y territoriales en la provincia de Granada. Scripta Nova, XVI(390). Retrieved from http://www.ub.edu/geocrit/sn/sn-390.htm

Cejudo, E., Navarro, F., \& Cañete, J. A. (2016). Evolución y distribución territorial de los trabajadores eventuales agrarios subsidiados en Andalucía. Boletín de la Asociación de Geógrafos Españoles, 72, 117-147. doi: http://dx.doi.org/10.5209/AGUC.57726

Cejudo, E., Navarro, F., \& Camacho, J. A. (2017). Perfil y características de los beneficiarios finales de los Programas de Desarrollo Rural en Andalucía LEADER + y PRODER2 (2000-2006). Cuadernos Geográficos, 56(2), 155-175.

Copus, A. K. (2008). Marco teórico-conceptual. In J. Noguera, \& J. Esparcia, J., Nuevos Factores de desarrollo territorial (pp. 31-58). Valencia: Universidad de Valencia.

Copus, A. K., Melo, P. C., Kaup, S., \& Tagai, G. (2015). Regional poverty mapping in Europe. Challenges, advances, benefits and limitations. Local Economy, 30(7), 742-764. doi: http://dx.doi.org/10.1177/0269094215601958

Cruces, C., \& Palenzuela, P. (2006). Emprendedoras rurales en Andalucía. Posibilidades y límites de sus estrategias. Revista de Estudios Agrosociales y Pesqueros, 211, 239-305.

Currie-Alder, B. (2016). The state of development studies: origins, evolution and prospects. Canadian Journal of Development Studies, 37(1), 5-26. doi: http://dx.doi.org/10.1080/02255189.2016.1135788

Dargan, L., \& Shucksmith, M. (2008). "Leader and innovation". Sociologia Ruralis, 48(3), 274291. doi: http://dx.doi.org/10.1111/j.1467-9523.2008.00463.x

Daz, T., \& Copus, A. K. (2016). The future of rural development policy. In Agriculture and rural development. Directorate-General for internal policies policy department b: Structural and cohesion policies agriculture and rural development (Workshop documentation). doi: http://dx.doi.org/10.2861/719222

Dirección General de Desarrollo Sostenible (2000-2008). Base de datos de la Consejería de Agricultura, Pesca y Desarrollo Rural de la Junta de Andalucía [Base de datos de acceso privado]. 
Esparcia, J., Noguera, J., \& Pitarch, M. D. (2000). Leader en España: desarrollo rural, poder, legitimación, aprendizaje y nuevas estructuras. Documentos de Análisis Geográfico, 37, 95-113. Retrieved from hittps://ddd.uab.cat/pub/dag/02121573n37/02121573n37p95.pdf

Esparcia, J., \& Escribano, J. (2012). La dimensión territorial en la programación comunitaria y el nuevo marco de políticas públicas: desarrollo rural territorial, reforma de la PAC y nuevo LEADER.Anales de Geografía, 227-252. doi: http://dx.doi.org/10.5209/rev_AGUC.2012.v32.n2.39719

Esparcia, J., Escribano, J., \& Buciega, A. (2015). A perspective of LEADER Method in Spain based on the Analysis of Local Action Groups. In L. Granberg, K. Andersson, \& I. Kovach (Eds.), Evaluating the LEADER Approach to Rural Development. Grass-roots Experiences of the LEADER Programme (pp. 33-51). New York: Ashgate Publisher.

Foronda, C. (2015) Experiencias investigadoras en capital social. In F. Leco (Ed.), Territorio y desarrollo rural: aportaciones desde el ámbito investigador (pp. 69-86). Cáceres: Junta de Extremadura.

Foronda-Robles, C., Pérez de Azpillaga, L. G., García López, A. M., \& Márquez Fernández, D. (2006). El precio de la sostenibilidad rural en Andalucía: el valor de LEADER II. Boletín de la Asociación de Geógrafos Españoles, 41, 295-313. Retrieved from http://www.agegeografia.es/ojs/index.php/bage/article/view/2001/1914

Gardner, G. (2011). Community action in rural Wales. In P. Milbourne (Ed.), Rural Wales in the twenty-first century. Society, economy and environment (pp. 81-112). Cardiff: University of Wales.

Gordo, P. (2011). Las políticas territoriales de desarrollo rural de la Unión Europea: un balance de 20 años en Castilla y León. Estudios de Economía Aplicada, 29(1), 7-30.

Guinjoan, E., Badía, A., \& Tulla, A. F. (2016). El Nuevo paradigma del desarrollo rural. Reflexión teórica y reconceptualización a partir de Rural Web. Boletín de la Asociación de Geógrafos Españoles, 71, 179-204. doi: http://dx.doi.org/10.21138/bage.2279

Guzmán, J., \& Romero, I. (2005). La trascendencia económica del trabajo autónomo. Temas Laborales, 81, 79-98.

Harvey, D. (2006) Spaces of Global Capitalism: Towards a Theory of Uneven Geographical Development. London: Verso.

Kitchen, L., \& Marsden, T. (2009). Creating Sustainable Rural Development through Stimulating the Eco-economy: Beyond the Eco-economic Paradox? Sociologia Ruralis, 49(3), 273-294. doi: http://dx.doi.org/10.1111/j.1467-9523.2009.00489.x

Lynch, J. (2006). Age in the Welfare State. Cambridge: Cambridge University Press. 
Marí-Klose, P. (2012). Prioridades poco prioritarias. Jóvenes en la agenda gubernamental en España (1982-1996). Revista Española de Investigaciones Sociológicas, 140, 69-88. doi: http://dx.doi.org/10.5477/cis/reis. 140.69

Martinez, F., Sacristán, H., \& Yagüe, J. L. (2015). Are local action groups, under LEADER approach, a good way to support resilience in rural areas? Ager, 18, 39-63. doi: http://dx.doi.org/10.4422/ager.2015.06

Ministerio de Medio Ambiente y Medio Rural y Marino (2011). Diagnóstico de la igualdad de género en el medio rural. Madrid: MARM.

Ministerio de Medio Ambiente y Medio Rural y Marino (2012). LEADER en España (1991-2011). Una contribución activa al desarrollo rural. Madrid: MARM.

Myles, J. (1984). Old Age in the Welfare State: The Political Economy of Public Pensions. Boston: Little Brown.

Nardone, G., Sisto, R., \& Lopolito, A. (2010). Social capital in the Leader Initiative: a methodological approach. Journal of Rural Studies, 26, 63-72. doi: http://dx.doi.org/10.1016/j.jrurstud.2009.09.001

Navarro, F., Cejudo, E., \& Maroto, J. (2014). Reflexiones en torno a la participación en el desarrollo rural. ¿Reparto social o reforzamiento del poder? LEADER y PRODER en el sur de España. Eure, 40(121), 203-224.

Navarro, F., Woods, M., \& Cejudo, E. (2016). The LEADER Initiative has been a victim of its own success. The decline of the bottom-up approach in rural development programmes. The cases of Wales and Andalusia. Sociologia Ruralis, 56(2), 270-288. doi: http://dx.doi.org/10.1111/soru. 12079

OCDE (2008). Growing Unequal? Income Distribution and Poverty in OECD Countries. Paris: OCDE.

Osti, G. (2000). Leader and partnerships: the case of Italy. Sociologia Ruralis, 40(2), 172-180. doi: http://dx.doi.org/10.1111/1467-9523.00139

Pita, M. F., \& Pedregal, B (coord. 2011). Tercer Informe de Desarrollo Territorial de Andalucía. Sevilla: Universidad de Sevilla.

Pita, M. F., \& Pedregal, B. (2015). La medición de la cohesión territorial a escala regional. Propuesta metodológica y aplicación a Andalucía. Boletín de la Asociación de Geógrafos Españoles, 68, 31-55.

Palenzuela, P., \& Cruces, C. (2011). Mujeres políticas y desarrollo rural en Andalucía. Revista Internacional de Sociología, 69(2), 487-515. doi: http://dx.doi.org/10.3989/ris.2009.03.05 
Plaza, J. I. (2006). Territorio, geografía rural y políticas públicas. Desarrollo y sustentabilidad en las áreas rurales. Boletín de la Asociación de Geógrafos Españoles, 41, 69-95.

Prieto, C., \& Pérez De Guzmán, S. (2013). Desigualdades laborales de género, disponibilidad temporal y normatividad social. Revista Española de Investigaciones Sociológicas, 141, 113-132. doi: http://dx.doi.org/10.5477/cis/reis. 141.113

Rico, M., \& Gomez-Limón, J. A. (2011). Propuesta metodológica para la construcción de indicadores sintéticos de igualdad de género en la España rural. El caso del medio rural de Castilla y León. Revista Internacional de Sociología, 69(1), 253-286. doi: http://dx.doi.org/10.3989/ris.2009.04.27

Riesco, A. (2016). Trabajo, independencia y subordinación. La regulación del trabajo autónomo en España. Revista Internacional de Sociología, 74(1), 1-14. doi: http://dx.doi.org/10.3989/ris.2016.74.1.026

Rodríguez, M., Tejero, O., \& Sánchez, I. (2014). Contingencia y crisis. Apuntes para una sociología atenta al fracaso y a lo imprevisto. Revista Española de Investigaciones Sociológicas, 147, 89-106. doi: http://dx.doi.org/10.5477/cis/reis. 147.89

Sabaté, A. (2009). La dimensión de género en las políticas españolas y europeas de desarrollo rural. In Mujeres en la actividad agraria y el mundo rural. Un camino de progreso e igualdad. Agricultura Familiar en España 2009. Madrid: Fundación de Estudios Rurales.

Sampedro, R. (2008). Conciliación de la vida familiar y laboral en el medio rural: género, trabajo invisible e "idilio rural". In V. Frades (Coord.), Mujeres rurales. Estudios multidisciplinares de género (pp. 81-93). Salamanca: Universidad de Salamanca.

Sampedro, R., \& Camarero, L. (2007). Mujeres empresarias en la España actual. El sujeto pendiente del Desarrollo. Revista Internacional de Sociología, XXV(48), 121-146. doi: http://dx.doi.org/10.3989/ris.2007.i48.71

Smith, N., \& Harvey, D. (2008). Uneven Development: Nature, Capital and the Production of Space (3rd Edition). Athens \& London: The Uniniversity of Georgia.

Sparrer, M. (2003). Género y turismo rural. El ejemplo de la costa coruñesa. Cuadernos de Turismo, 11, 181-197.

Tellmann, K. (2012). Measuring social capital accumulation in rural development. Journal of Rural Studies, 28(4), 458-46. doi: http://dx.doi.org/10.1016/j.jrurstud.2012.10.002

Woods, M. (2011). Rural. Oxon \& Nueva York: Routledge. 